\title{
¿On the Extreme Rainfall Event of 7 May 2017 over the Coastal City of Guangzhou. Part I: Impacts of Urbanization and Orography
}

\author{
JINFANG YIN \\ State Key Laboratory of Severe Weather, Chinese Academy of Meteorological Sciences, Beijing, China
}

DA-LIN ZHANG

Department of Atmospheric and Oceanic Science, University of Maryland, College Park, College Park, Maryland, and State Key Laboratory of Severe Weather, Chinese Academy of Meteorological Sciences, Beijing, China

\section{YALI LUO AND RUOYUN MA}

State Key Laboratory of Severe Weather, Chinese Academy of Meteorological Sciences, Beijing, China

(Manuscript received 24 June 2019, in final form 23 December 2019)

\begin{abstract}
In this study, a nocturnal extreme rainfall event induced by the urban heat island (UHI) effects of the coastal city of Guangzhou in South China on 7 May 2017 is examined using observational analyses and 18-h cloud-permitting simulations with the finest grid size of $1.33 \mathrm{~km}$ and the bottom boundary conditions nudged. Results show that the model reproduces convective initiation on Guangzhou's downstream side (i.e., Huashan), where a shallow thermal mesolow is located, the subsequent back-building of convective cells as a larger-scale warm-moist southerly flow interacts with convectively generated cold outflows, and their eastward drifting and reorganization into a localized extreme-rain-producing storm near Jiulong under the influences of local orography. In particular, the model produces the maximum hourly, 3- and 12-hourly rainfall amounts of 146,315 , and $551 \mathrm{~mm}$, respectively, at nearly the right location compared to their corresponding observed extreme amounts of 184,382 , and $542 \mathrm{~mm}$. In addition, the model reproduces an intense meso- $\gamma$-scale vortex associated with the extreme-rain-producing Jiulong storm, as also captured by Doppler radar, with organized updrafts along cold outflow boundaries over a semicircle. A comparison of sensitivity and control simulations indicates that despite the occurrence of heavier rainfall amounts without the UHI effects than those without orography, the UHI effects appear to account directly for the convective initiation and heavy rainfall near Huashan, and indirectly for the subsequent formation of the Jiulong storm, while orography plays an important role in blocking cold outflows and enhancing cool pool strength for the sustained back-building of convective cells over the semicircle, thereby magnifying rainfall production near Jiulong.
\end{abstract}

\section{Introduction}

An extreme rainfall (ER) event occurred over the coastal city of Guangzhou during the early morning hours of 7 May 2017, with record-breaking 3- and 12-h accumulated amount of 382 and $542 \mathrm{~mm}$, respectively, for Guangdong Province. An hourly rainfall rate of $184 \mathrm{~mm} \mathrm{~h}^{-1}$ at Jiulong (see Fig. 1) is close to the highest

¿ Denotes content that is immediately available upon publication as open access.

Corresponding author: Da-Lin Zhang, dalin@umd.edu rate of $188 \mathrm{~mm} \mathrm{~h}^{-1}$ recorded at Yangjiang, Guangdong Province, on 23 June 2013. In addition, 12 rain gauge stations recorded total accumulated rainfall amounts exceeding $250 \mathrm{~mm}$, with the two centers of 542 and $341 \mathrm{~mm}$ occurring near Jiulong (JL) and Huashan (HS), respectively (Fig. 1); the two centers are about $36 \mathrm{~km}$ apart. Due to their different rainfall rates, Jiulong and Huashan are referred herein to as the centers of ER and heavy rainfall generation category, respectively.

This article is licensed under a Creative Commons Attribution 4.0 license (http://creativecommons.org/ licenses/by/4.0/) 


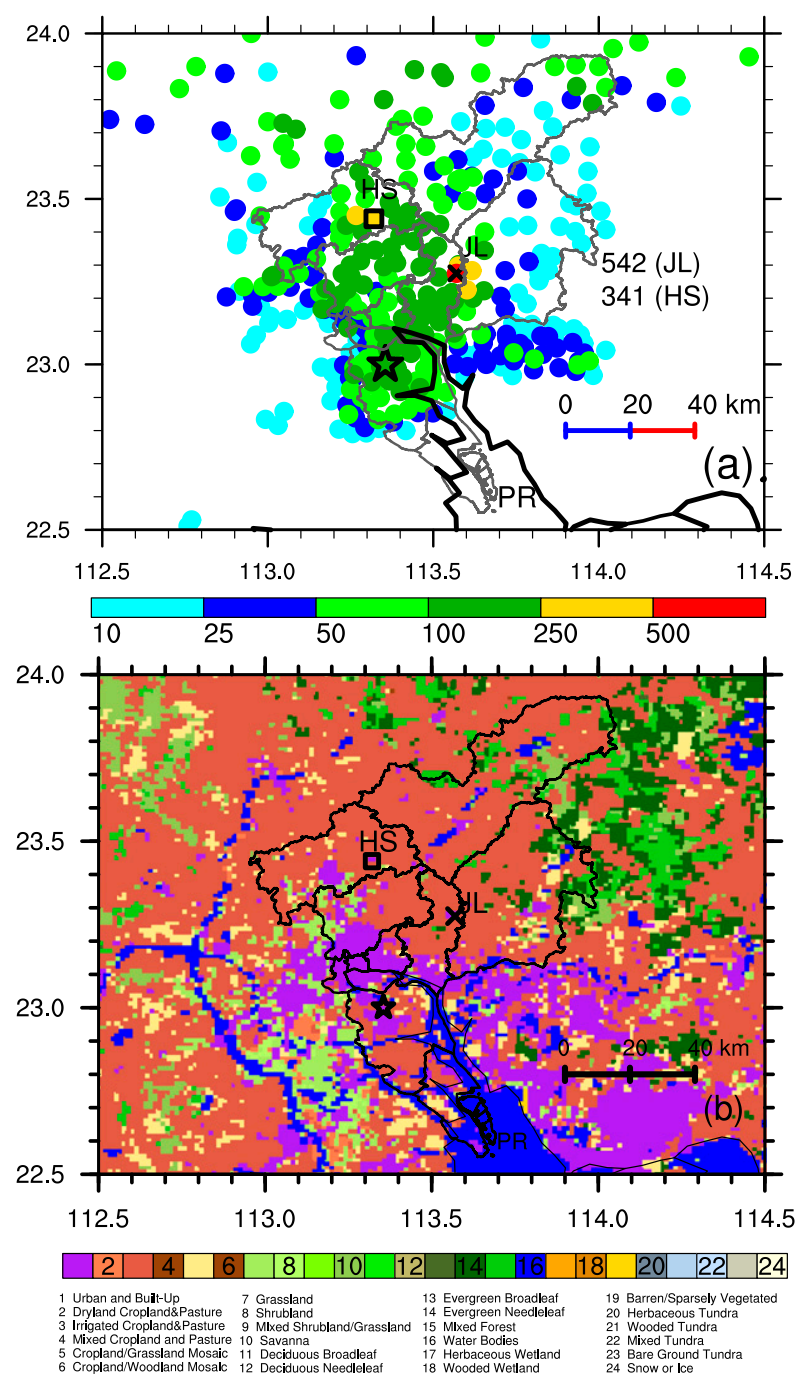

FIG. 1. Distribution of (a) the 18-h accumulated rainfall (mm, colored dots) during the period of 2000 BST 6 May to 1400 BST 7 May 2017; and (b) the dominant land use around the Guangzhou region from the U.S. Geological Survey. A crisscross sign $(\times)$ and a square sign $(\square)$ denote the locations where the maximum accumulated rainfalls of 542 and $341 \mathrm{~mm}$ were observed near Jiulong (JL) and Huashan (HS), respectively. A star indicates the city center of Guangzhou with its district borders given by thin gray lines, and the Pearl River is marked by PR; similarly for the rest of figures.

Although heavy rainfall events occurred frequently in South China (Luo et al. 2017), there were three distinct features associated with Guangzhou's ER event: (i) its initiation and growth on the downwind side of Guangzhou; (ii) the ER production from localized convective storms with life spans of more than $10 \mathrm{~h}$; and (iii) the quasi-stationary nature of the ER production near Huashan and Jiulong. Moreover, this ER event occurred in a warm sector (i.e., far ahead of a surface front), with weak-gradient flows, namely, lacking quasigeostrophic forcing (e.g., midlevel trough, surface frontal passage). As could often be expected, all the then operational models predicted little precipitation over the Pearl River Delta (PRD), where Guangzhou City is surrounded with trumpet-shaped mountains in the north, even $12 \mathrm{~h}$ in advance, so did local weather forecasters. Thus, several questions have been raised after the ER event: In the absence of large-scale lifting, what mechanism(s) accounted for the convective initiation and the subsequent ER production? Given the presence of weak-gradient flows, where was the source of moisture supply associated with Guangzhou's ER event? How could such an ER event take place in such localized convective storms? Thus, we are motivated to conduct this modeling study to address these questions.

Given the ER production in the vicinity of Guangzhou, we may hypothesize the importance of its UHI effects and northern mountains, and the needed moisture supply from the moist planetary boundary layer (PBL) over the South China Sea in determining the convective initiation and subsequent generation of the ER event. The UHI effects refer to as the increased warmth and elevated depth of the PBL, and the convergence of surface flows relative to nearby rural areas (Oke 1987; Bornstein and Lin 2000; Arnfield 2003; D.-L. Zhang et al. 2011; Li et al. 2017a,b; Garuma 2018), and sometime more clouds with higher bases than over surrounding rural regions (Angevine et al. 2003). The UHI effects leading to increased precipitation during the summer months have been known since the early 1980s, especially after the Metropolitan Meteorological Experiment (METROMEX; Braham et al. 1981). More studies have since continued to confirm and to enrich those findings (Shepherd 2005). Previous studies showed that rapid urban expansion over the PRD and elsewhere has produced significant influences on the low-level winds and surface temperature (e.g., Lo et al. 2007; Wu et al. 2011; H. Zhang et al. 2019). Some regional climate studies have provided evidence of increased frequency of heavy rainfall events in the vicinity of large cities, including Guangzhou and Shanghai (Wang et al. 2015; Liang and Ding 2017; Wu et al. 2019).

Although several field experiments have been conducted to examine the generation of heavy precipitation in mesoscale convective systems (MCSs) over South China (Huang 1986; Zhou et al. 2003; R. Zhang et al. 2011; Luo 2017; Luo et al. 2017), little attention has been given to the development of localized ER-producing storms. In particular, few case studies have been performed to examine the relative roles of the UHI effects and orography in determining the initiation and subsequent development of those storms during nocturnal periods in South China. After all, the rapid urban 
expansion over the region has only occurred in the recent few decades (Wu et al. 2019). Thus, the major objectives of the present study are to (i) determine to what extent the record-breaking rain-producing storms over Guangzhou on 7 May 2017 could be simulated with the most advanced weather prediction model; (ii) explore the multiscale processes, especially the UHI effects of Guangzhou and its northern mountains, governing the nocturnal convective initiation and subsequent ER production in the warm sector; and (iii) examine any nonobservable storm-scale flow structure(s) that are associated with the record-breaking rainfall production.

It should be mentioned that this ER case has been simulated by Huang et al. (2019) using the Weather Research and Forecasting (WRF) Model (Skamarock et al. 2008) with the finest grid size of $0.5 \mathrm{~km}$. Their results show that a large-scale southerly moist flow provided a favorable condition for energy supply and convective initiation. Convectively generated outflow boundaries interacted with the southerly flow to form a back-building storm, thereby leading to the ER event. Unlike what we hypothesized above, they concluded that the urban forcing was not a necessary factor for the initiation and generation of the ER-producing storm, and it only affected the timing, location and rainfall intensity. However, their control simulation appears to produce less than half the observed rainfall amounts near Huashan and Jiulong (see Fig. 10 therein).

The next section presents environmental conditions associated with the ER event. Section 3 describes model configurations and verifications against available observations. Mesoscale analyses of the observed and simulated surface fields are also shown. Section 4 provides a detailed analysis of convective initiation and the subsequent ER production near Huashan and Jiulong, respectively, from the control simulation. Section 5 presents the results of sensitivity experiments due to the UHI effects and topography. A summary and concluding remarks are given in the final section.

\section{Environmental conditions}

Figure 2 presents a weather chart at 2000 BST (Beijing standard time $=$ UTC $+8 \mathrm{~h}) 6$ May 2017, which was 3-4 $\mathrm{h}$ prior to the convective initiation of the present ER event under study. Large-scale flow patterns exhibited (i) a southwesterly flow at $700 \mathrm{hPa}$ with a weak smallscale disturbance around the PRD, as indicated by the geopotential height field, and little thermal advection over the southern coastal regions; (ii) an anticyclonic circulation with east- to southeasterly flows of $2-3 \mathrm{~m} \mathrm{~s}^{-1}$ at $900 \mathrm{hPa}$, and (iii) the presence of precipitable water (PW) of larger than $56 \mathrm{~mm}$ on the west and $52 \mathrm{~mm}$ over

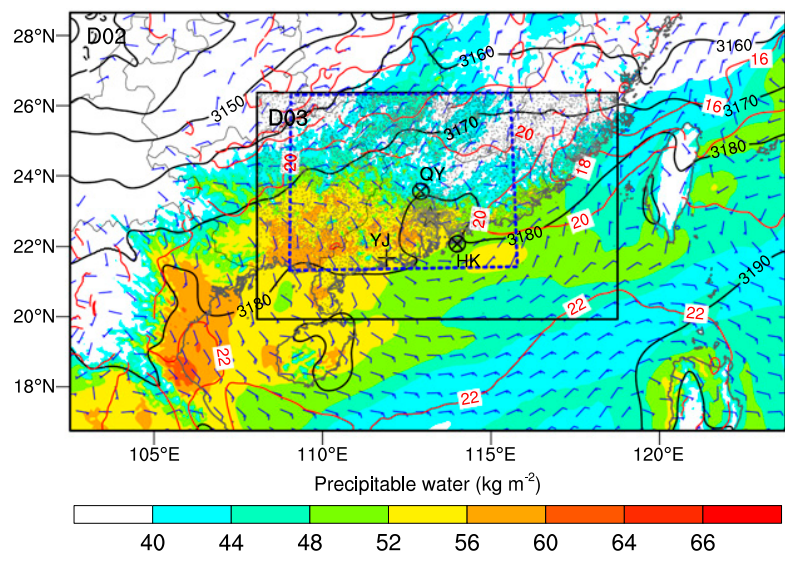

FIG. 2. Nested model domains used for the WRF simulations are marked by black rectangles with the grid resolution of $4 \mathrm{~km}$ (D02) and $1.333 \mathrm{~km}$ (D03), respectively. They are superimposed with the National Centers for Environmental Prediction Global Forecast System Final (NCEP-FNL) analysis at 2000 BST 6 May 2017: Geopotential height (black contoured at $10-\mathrm{m}$ intervals) at $700 \mathrm{hPa}$, temperature (red dash contoured at $2{ }^{\circ} \mathrm{C}$ intervals) and wind barbs (a full barb is $4 \mathrm{~m} \mathrm{~s}^{-1}$ ) at $900 \mathrm{hPa}$, and precipitable water $\left(\mathrm{kg} \mathrm{m}^{-2}\right.$, shadings). The dashed inner box denotes an area, in which terrain is removed for the sensitivity experiment of NTER shown in Fig. 18f. The circle-cross markers represent the locations of radiosonde stations at Hong Kong (HK) and Qingyuan (QY). The plus symbol $(+)$ denotes the location of Yangjiang (YJ) station, at which a maximum hourly rainfall of $188 \mathrm{~mm}$ was recorded on 23 Jun 2013.

the coastal water on the south of the PRD. Clearly, the present ER event took place over a weak-gradient environment with little quasigeostrophic forcing, as mentioned in section 1 .

Figure 3 shows two 2000 BST 6 May upper-air soundings taken at Hong Kong and Qingyuan stations, which are located about 121 and $84 \mathrm{~km}$ to the respective southeast and near-north of Guangzhou (see Fig. 2 for their relative locations). As will be shown in the next two sections, Hong Kong was more or less located on the upstream of the current ER-producing storms. Both soundings showed the development of a well-mixed PBL (shallower at Hong Kong, and up to $900 \mathrm{hPa}$ at Qingyuan) at this early evening hour, with the convective available potential energy (CAPE) of 1647 and $1503 \mathrm{~J} \mathrm{~kg}^{-1}$ and the convective inhibition (CIN) of 23 and $7 \mathrm{~J} \mathrm{~kg}^{-1}$ at Qingyuan and Hong Kong, respectively. In particular, the two soundings revealed the presence of conditional instability in the vicinity of Guangzhou, as indicated by negative lifted indices (LI) and large $K$-index values, with small dewpoint depressions or close to saturation conditions in the lowest $300-\mathrm{hPa}$ layer. Note that the upstream PW value (i.e., at Hong Kong), was as high as $53 \mathrm{~mm}$ (Fig. 3a). This is close to the estimated 60-mm PW associated with the Beijing extreme rainfall of 21 July 2012, in which a recording-breaking amount of 

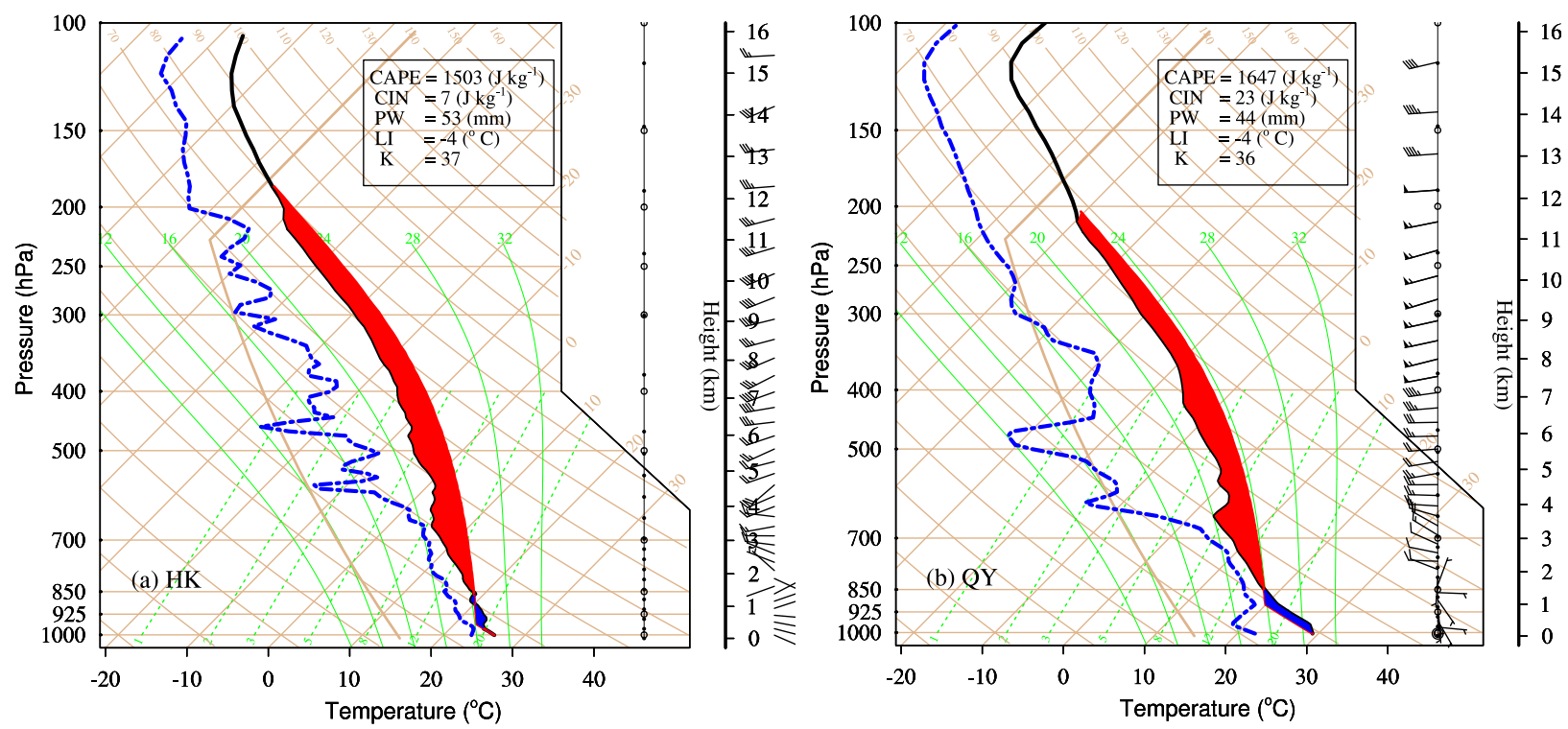

FIG. 3. Skew $T-\log p$ diagrams obtained at (a) Hong Kong and (b) Qingyuan at 2000 BST 6 May 2017 (see Fig. 2 for their locations). A full wind barb denotes $4 \mathrm{~m} \mathrm{~s}^{-1}$. Shadings in red and blue are for CAPE and CIN, respectively.

$460 \mathrm{~mm}$ in $18 \mathrm{~h}$ and hourly rainfall rates of over $85 \mathrm{~mm}$ were observed (Zhang et al. 2013; Zhong et al. 2015).

All the above features indicate clearly that the prestorm environmental conditions were favorable for convective development when lifting to the lifting condensation level (LCL) could be provided. With the presence of little quasigeostrophic lifting (Fig. 2), the low-level southeasterly flow (i.e., below $750 \mathrm{hPa}$ ) was too weak (Fig. 3b) (i.e., less than $3 \mathrm{~m} \mathrm{~s}^{-1}$ ) to provide the needed convergence and upward lifting in order to overcome the existing CIN, albeit small, unless meeting with orography. This explains why no widespread convective activity with ER occurred over a large portion of the PRD, despite the presence of conditional instability with large CAPE and high PW. A wind directional shift from southeasterly to westerly appeared near $750 \mathrm{hPa}$, which is more or less consistent with the anticyclonic flow at $900 \mathrm{hPa}$ shown in Fig. 2.

We may assume that the above large-scale features should be reasonably represented by the then operational models, which can be seen to a certain extent from the National Centers for Environmental Prediction's (NCEP) Global Forecast System final $0.25^{\circ}$ (NCEPFNL) reanalysis given in Fig. 2. The failure of the then operational models in reproducing the ER event appears to be attributed to the lacking maintenance of Guangzhou's UHI effects in addition to the too coarse grid resolutions used. To test this hypothesis and address the questions raised in section 1 , we have to invoke the use of cloud-permitting simulations to examine the roles of Guangzhou's UHI and its northern mountains in determining the convective initiation and subsequent ER development.

\section{Model description and verification}

\section{a. Model description}

The 7 May 2017 ER event is simulated using a two-way interactive, triply nested version of the WRF-ARW(v3.9.1) model with the respective grid size of 12,4 , and $1.33 \mathrm{~km}$. Figure 2 also shows the geographical coverage of the innermost two domains (i.e., D02 and D03), with the finest-resolution domain covering an $(x, y)$ area of $1148 \mathrm{~km} \times 720 \mathrm{~km}$. The outermost domain (i.e., D01) covers an $(x, y)$ area of $3756 \mathrm{~km} \times 2424 \mathrm{~km}$ with $313 \times$ 202 grid points (not shown), and it is centered at $23^{\circ} \mathrm{N}$, $110^{\circ} \mathrm{E}$. A total of 57 sigma levels is used in the vertical with 15 levels below $850 \mathrm{hPa}$, and 9 levels between $200 \mathrm{hPa}$ and the model top at $20 \mathrm{hPa}$ (Yin et al. 2018). The model physics schemes used include (i) the Kain (2004) cumulus parameterization scheme in the outer two coarse-resolution domains, but being bypassed in the finest-resolution domain; (ii) the new Thompson microphysical scheme (Thompson et al. 2008); (iii) the rapid radiative transfer model (Mlawer et al. 1997) for both shortwave and longwave radiative flux calculations; (iv) the Yonsei University PBL scheme (Hong et al. 2006); (v) the MM5 Monin-Obukhov similarity scheme for the surface layer (Zhang and Anthes 1982); and (vi) the Noah-MP land surface scheme (Niu et al. 2011).

All the three nested domains of the WRF Model are integrated for $18 \mathrm{~h}$, starting from 2000 BST 6 May, with 


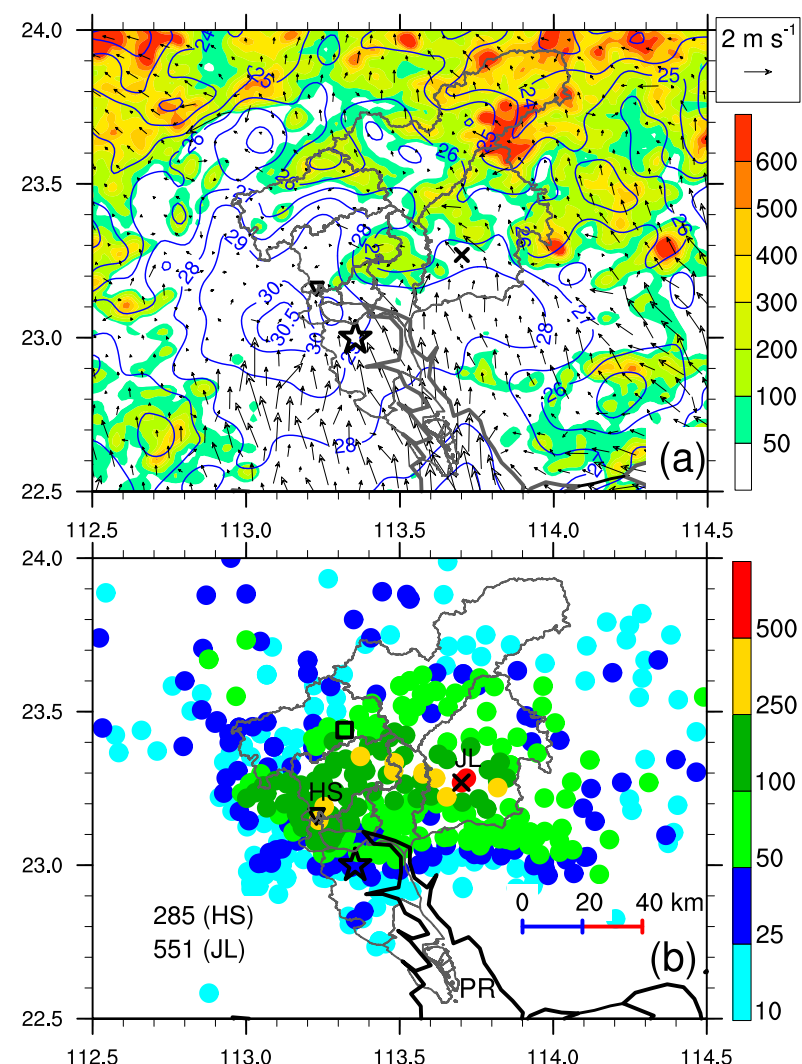

FIG. 4. (a) Surface temperature (blue contoured at $1^{\circ} \mathrm{C}$ intervals) and horizontal wind vectors at the model initial time, and topography ( $\mathrm{m}$, color shadings), and (b) as in Fig. 1a, but for the accumulated rainfall amount ( $\mathrm{mm}$, colored dots) from the 18-h simulations of 2000 BST 6 May-1400 BST 7 May 2017. Note that the symbol, $\nabla$, is used to indicate the location of Huashan (HS) in the model.

outputs at 6-min intervals. The initial and outermost boundary conditions are interpolated from the NCEPFNL $0.25^{\circ}$ analysis data at 6 -h intervals. To introduce realistically Guangzhou's UHI effects due to the release of daytime-absorbed sensible heat by urban structures and anthropogenic heat during the evening hours, the four-dimensional data assimilation (FDDA) functions are activated (Stauffer and Seaman 1990; Seaman et al. 1995) by performing both the surface observation nudging and the (surface) grid analysis nudging from 2000 BST 6 May to 0800 BST 7 May 2017. The required analysis data are obtained through the WRF's preprocessing OBSGRID module (Reen 2016; Wang et al. 2017), using the hourly surface automated weather station (AWS) observations that are archived by the National Meteorological Information Center of China after performing data quality control. About 7200 AWS observed surface temperature, relative humidity, and horizontal winds, over domain D3 are used. No other data are assimilated into the model,

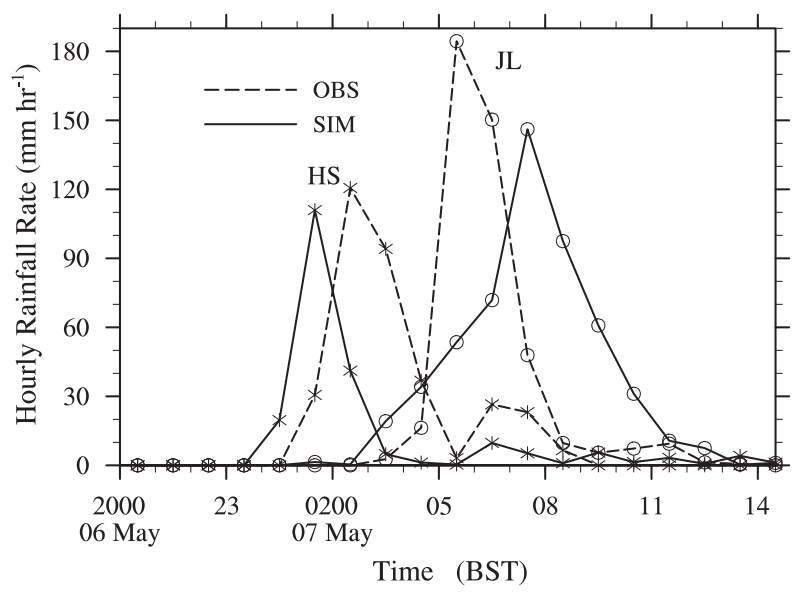

FIG. 5. Time series of the rain gauge (dashed) and simulated (solid) hourly rainfall rates $\left(\mathrm{mm} \mathrm{h}^{-1}\right)$ near Jiulong(JL) and Huashan (HS) during the period of 2000 BST 6 May-1400 BST 7 May 2017 (see Fig. 1a for their locations).

unlike the simulations of Huang et al. (2019) in which surface observations, soundings, and wind profiles were all assimilated from 2000 BST 6 May to 0800 BST 7 May in their outer domains and from 2000 BST 6 May to 0000 BST 7 May 2017 in their innermost domain.

Figure 4a shows the map of surface temperature and horizontal wind vectors at the model initial time (i.e., shortly after sunset). Of relevance to this study is that Guangzhou City was covered by pronounced warm air, especially over its central business district (CBD), the so-called UHI effects, with the peak surface temperature of over $30.5^{\circ} \mathrm{C}$ or $5^{\circ}-6^{\circ} \mathrm{C}$ warmer than its rural areas. Of further relevance is the presence of systematic surface south-to-southeasterly flows of oceanic origin, albeit $2-4 \mathrm{~m} \mathrm{~s}^{-1}$, but very weak or near-calm flows on the northern side of Guangzhou City. The two rainfall centers (i.e., near Jiulong and Huashan), were just located on the northern suburban regions, where significant wind convergence was present. These features suggest the possible impact of the UHI on the development of the present rainfall event, when considering sufficient moisture supply from the moist inflows of oceanic origin. Figure 4a also shows that Guangzhou City is centered over a plain area with the Pearl River on the southeast, a few scattered hills of $200-400 \mathrm{~m}$ altitudes at $20-50 \mathrm{~km}$ to the northeast, and the trumpetshaped higher mountains farther away in the north. While the general surrounding topography may affect the regional flows in the PBL (e.g., mountain-plain flows and up/down valley winds), the Pearl River and nearby hills of $200-400 \mathrm{~m}$ elevations may have some more direct impacts of the development of the associated ER-producing storms (e.g., near Jiulong) where it 


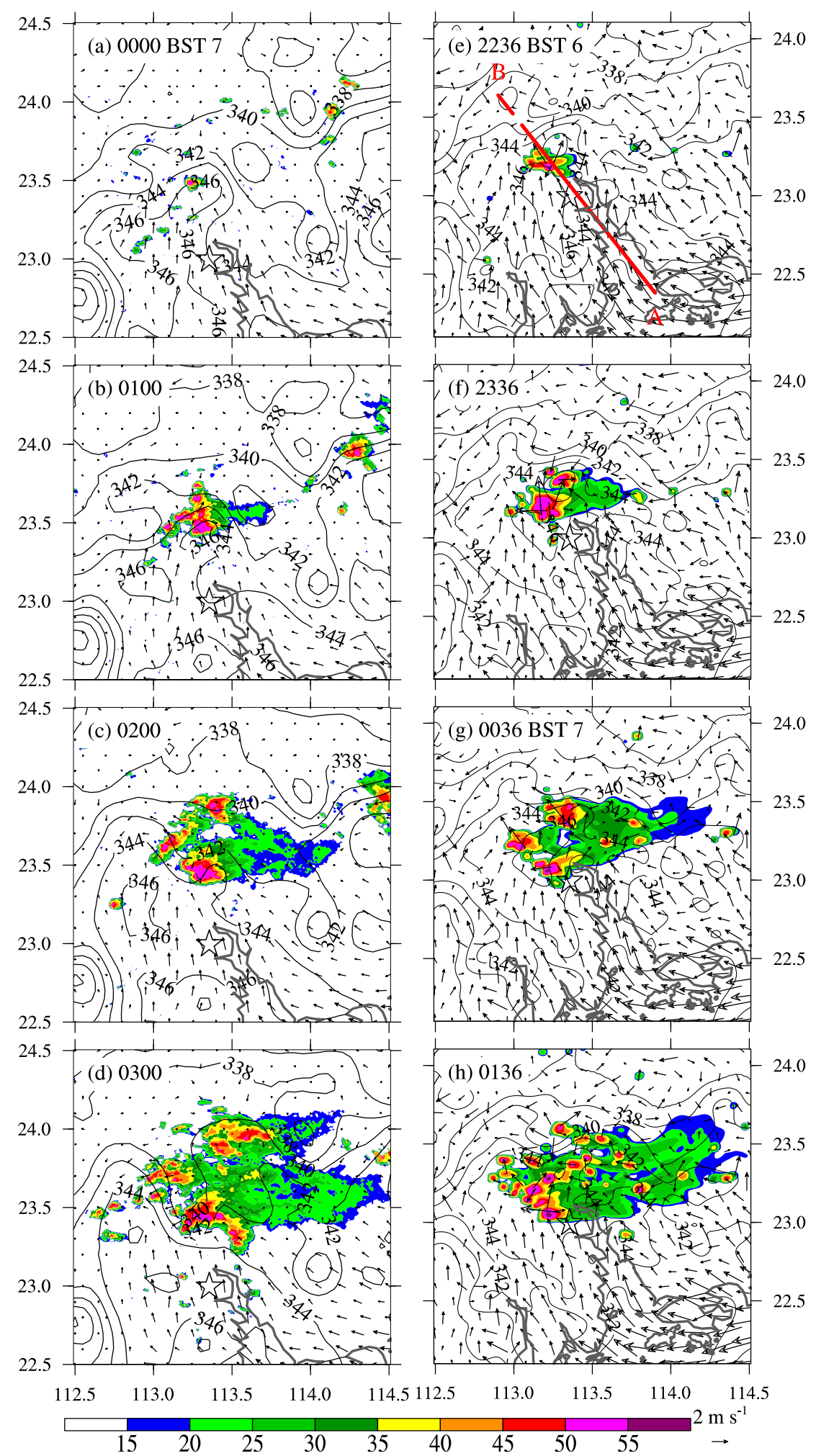

FIG. 6. Horizontal maps of the (left) observed and (right) simulated composite radar reflectivity ( $\mathrm{dB} Z$, shadings), surface $(z=10 \mathrm{~m})$ horizontal wind vectors, and surface $(z=2 \mathrm{~m})$ equivalent potential temperature $\left(\theta_{e}\right.$, contoured at $2 \mathrm{~K}$ intervals $)$ during the initial convective development stage (i.e., from 2236 BST 6 May to 0300 BST 7 May 2017). Note an approximate shift of $0.4^{\circ}$ latitude and $1.4 \mathrm{~h}$ between the simulation and observation 
is located in a valley with surrounding hills except on the south.

\section{b. Model verification and mesoscale analysis}

Figure $4 \mathrm{~b}$ shows the simulated 18 -h accumulated rainfall that can be compared to that shown in Fig. 1. In general, the model reproduces reasonably well the spatial distribution of heavy rainfall, especially for a 100-250 mm rainfall belt through Huashan and Jiulong. The simulated ER amount compares favorably to the observed near Jiulong, with only a $3-5 \mathrm{~km}$ location error. In particular, the model simulates a peak 12-h accumulated value of $551 \mathrm{~mm}$, as compared to the observed maximum value of $542 \mathrm{~mm}$. This simulated pointwise peak rainfall amount should be adequate, since the real ER amount may not be captured by the surface observing network. In addition, a secondary ER amount of over $285 \mathrm{~mm}$ near Huashan is reproduced, although the simulated rainfall center is located at about $30 \mathrm{~km}$ to the southwest of the observed. We may argue that these location errors are acceptable, given the fact that the model atmosphere above the PBL is initialized with large-scale meteorological conditions (i.e., the NCEPFNL analysis). In the next sections, we will examine how the two ER centers are produced, with more focus on the ER center near Jiulong.

Figure 5 compares the time series of hourly maximum rainfall rates between the observed and simulated at the abovementioned two ER stations. The observed peak rainfall episodes near Huashan and Jiulong occurred at 0300 and 0600 BST 7 May with the hourly rates of 120 and $184 \mathrm{~mm} \mathrm{~h}^{-1}$, respectively, whereas the corresponding two simulated peak rainfall episodes take place at 0200 and 0800 BST 7 May, which are about $1 \mathrm{~h}$ earlier and $2 \mathrm{~h}$ later than the observed, with the respective hourly rates of 111 and $146 \mathrm{~mm} \mathrm{~h}^{-1}$. While the model underpredicts the peak hourly rainfall rate near Jiulong, the observed timings of initiating and ending of the ER production (i.e., near 0300 and 1000 BST 7 May, respectively) are reproduced successfully. The simulated peak rate occurs $2 \mathrm{~h}$ later than the observed near Jiulong, because of the slower increases in rain-producing rates than the observed. That is, the observed hourly rate near Jiulong increased from about 3 to $184 \mathrm{~mm} \mathrm{~h}^{-1}$ just in one hour (i.e., from 0500 to 0600 BST), whereas the simulated one increases from $1 \mathrm{~mm} \mathrm{~h}^{-1}$ at 0400 BST to about $71 \mathrm{~mm} \mathrm{~h}^{-1}$ at $0700 \mathrm{BST}$, and then to $146 \mathrm{~mm} \mathrm{~h}^{-1}$ at $0800 \mathrm{BST}$
7 May. This difference in reaching the peak rainfall rate could be attributed to differences in larger-scale moisture supply rates, rain-producing rates and the propagation speed of passing-by convective cells. On the other hand, both the observed and simulated rainfall rates decrease in a similar fashion, albeit with one hour delay from its peak value to smaller one for the latter.

Figure 6 shows the ability of the WRF Model to mimic the structures and evolution of convective cells by comparing the simulated composite radar reflectivity (CR) to the observed; the latter was integrated by combining four individual radar observations around Guangzhou City. The first well-defined radar echo formed at 0000 BST 07 May near Huashan, which was located at the northern edge of a surface high- $\theta_{e}$ (equivalent potential temperature) tongue with significant convergence (Fig. 6a). These scenarios are similar to those shown by previous studies (e.g., Braham et al. 1981; Yu and Liu 2015; Li et al. 2017a,b; Debbage and Shepherd 2019), showing that the downstream side of an urban area is a favorable location for convective initiation. The high $-\theta_{e}$ tongue, with a peak value of $346 \mathrm{~K}$ over Guangzhou's UHI region (cf. Figs. 6a-c and 4a), was clearly generated by the moist south-to-southeasterly flows of oceanic origin in the western half portion of Guangzhou City. Of course, this could be partly attributed to the assimilation of AWS observations. Once formed, the storm began its rapid development, with its peak radar reflectivity reaching over $50 \mathrm{dBZ}$ (Fig. 6b). Subsequently, several new convective cells, though relatively smaller sized, developed on the downstream of the above major one (Figs. 6c,d). Meanwhile, a growing coverage of trailing stratiform rainfall appeared on the east of the leading convective elements under the influence of the midtropospheric near-westerly flow (Fig. 3). Of importance is that all the convective cells, especially the major one, remained quasi-stationary for more than $3 \mathrm{~h}$ (i.e., from 0000 to $0300 \mathrm{BST}$ and beyond) after their formation (Figs. 6a-d). It appears to be the quasi-stationary characteristics of the major intense storm with the radar reflectivity of over $50 \mathrm{~dB} Z$ that accounted for the generation of large accumulated rainfall at Huashan. So, this storm of about $20 \mathrm{~km}$ wide is hereafter referred to as the Huashan storm, and it was clearly a meso- $\gamma$-scale system. Much less rainfall was generated by convective storms on the north due to the blocking of higher- $\theta_{e}$ air in the southerly flow by the

due to the simulated timing and position errors of convective development. A reference wind vector is given beneath the right column next to the composite radar reflectivity color scale. The red thick line A-B in (e) denotes the locations of vertical cross section used in Fig. 9. 
Huashan storm (cf. Figs. $6 \mathrm{c}, \mathrm{d}$ and 2). In fact, a lower- $\theta_{e}$ tongue occurred underneath the convective cells as a result of convectively generated cooling and drying in the PBL, as indicated by local outflow vectors (Fig. 6d). At the same time, another new intense convective cell was initiated on the southeast of the major one, which was later associated with an ERproducing storm near Jiulong, hereafter referred to as the Jiulong storm.

Similarly, the model simulates the convective initiation of several small-sized convective cells at the northern edge of a high- $\theta_{e}$ tongue, where pronounced wind convergence occurs at the interface between a moist southerly flow and a near-calm flow to the north (Fig. 6e). However, the first well-defined convective cell is initiated about $1 \mathrm{~h}$ earlier than the observed (Fig. 5), and slightly to the south of the observed (i.e., slightly to the north of Guangzhou's CBD) (cf. Figs. 6e,a). The differences of the simulated location and timing from the observed ones could be attributed to lacking higher-resolution observations in the model initial conditions, especially above the surface layer. Nevertheless, the general south to southeasterly inflows and high $-\theta_{e}$ tongue with the peak value of $346 \mathrm{~K}$ over Guangzhou's UHI region, which play an important role in determining the initiation and subsequent evolution of the storms, are represented successfully, due to the use of the surface dynamical nudging. Indeed, the model reproduces reasonably well the northward convective expansion and the subsequent arc-shaped meso- $\beta$-scale cloud system including all intense convective cells, the trailing stratiform rainfall to the east, and especially the quasi-stationary nature and the coverage of the Huashan storm (Figs. 6f-h), except for the same amounts of timing and location errors as those at the initiating stage (cf. Figs. 6d,h,a,e).

As the southeasterly flow axis with higher- $\theta_{e}$ air shifted slowly eastward and as a result of convectively generated cold outflows, the Huashan storm dissipated while the previously mentioned new convective cell to the southeast (i.e., the Jiulong storm) (Fig. 6d), began to expand in size, through backbuilding process (Schumacher et al. 2011; Huang et al. 2019), more southeastward after 0300 BST 7 May (cf. Figs. 6d and 7a). Despite its expansion, we may still consider the Jiulong storm as a meso- $\gamma$-scale storm of about $20 \mathrm{~km}$ in diameter shown by radar reflectivity of greater than $45 \mathrm{~dB} Z$. The Jiulong storm experienced rapid intensification between 0430 and 0530 BST, with the peak reflectivity reaching over $55 \mathrm{~dB} Z$ near the leading edge (Figs. 7a,b). The generation of a raining cloud system with over $55 \mathrm{~dB} Z$ reflectivity implies a doubling ${ }^{1}$ hourly rainfall rate compared to a 50-dBZ storm (e.g., the Huashan storm). Moreover, like the Huashan storm, the Jiulong storm kept more or less quasi-stationary shortly after its formation (Figs. 7a-d). Both the quasi-stationary nature and intense radar reflectivity explain the ER production rate occurring at Jiulong during the 1 -h period of 0430-0530 BST (cf. Figs. 7a,b and 5). Subsequently, the Jiulong storm weakened, but its associated peak radar reflectivity still remained over $50 \mathrm{~dB} Z$, which was consistent with the continued generation of significant rainfall near Jiulong until 0800 BST (Fig. 5).

It is apparent from Figs. 7e-h that the model reproduces the development of the Jiulong storm, with the general characteristics that are similar to the observed, such as its quasi-stationary nature, its southeastward expansion, and its meso- $\gamma$-scale size and reflectivity intensity at the ER producing stage (cf. Figs. $7 \mathrm{~g}, \mathrm{f}$ ). The model also reproduces the growth of a cloud system with a wide coverage of stratiform rainfall to the eastnortheast from meso- $\beta$ to meso- $\alpha$ scale (i.e., larger than $200 \mathrm{~km}$ from the west to east), and the changes in the arcshaped orientation from bulging westward to northward (Figs. 7d,h). The model even reproduces more or less a donut-shaped high-reflectivity ring to the northwest of the Jiulong storm (Figs. 7g,c), due likely to the outward expansion of the cold pool. However, the initiation and organization of the simulated Jiulong storm are about $1.7 \mathrm{~h}$ later than the observed, and it occurred at a location a few kilometers to the east of the observed one. They are consistent with the timing lag in the hourly ER production and the spatial error shown in Figs. 5 and $4 \mathrm{~b}$, respectively. Of significance is that the model reproduces a convectively generated lower- $\theta_{e}$ pool with a well-defined outflow boundary interacting with the moist southeasterly flow. Clearly, their interactive process plays an important role in the convective initiation and maintenance of deep convection associated with the organization of the ER-producing Jiulong storm, which will be explored in the next two sections. After dropping ER near Jiulong, both the observed and simulated convective systems move slowly southward, leaving behind another $100-250$ and $50-100 \mathrm{~mm}$ rainfall belt between Jiulong and Guangzhou's CBD, respectively (Figs. 7d,h).

\footnotetext{
${ }^{1}$ The doubling hourly rainfall rate from 50 to $55 \mathrm{~dB} Z$ is based on the classical power law relation between the radar reflectivity factor $(Z, \mathrm{~dB})$ of precipitation and rainfall rate $\left(R, \mathrm{~mm} \mathrm{~h}^{-1}\right)$ as proposed by Battan (1973) [i.e., the so-called $Z-R$ relationship as given by $Z=200 R^{1.6}$, where $\left.1 \mathrm{~dB}=10^{(\mathrm{dB} Z / 10)}\right]$. Thus, a 50 and a $55 \mathrm{~dB} Z$ value of radar reflectivity corresponds to a rainfall rate of 48.6 and $99.8 \mathrm{~mm} \mathrm{~h}^{-1}$, respectively.
} 


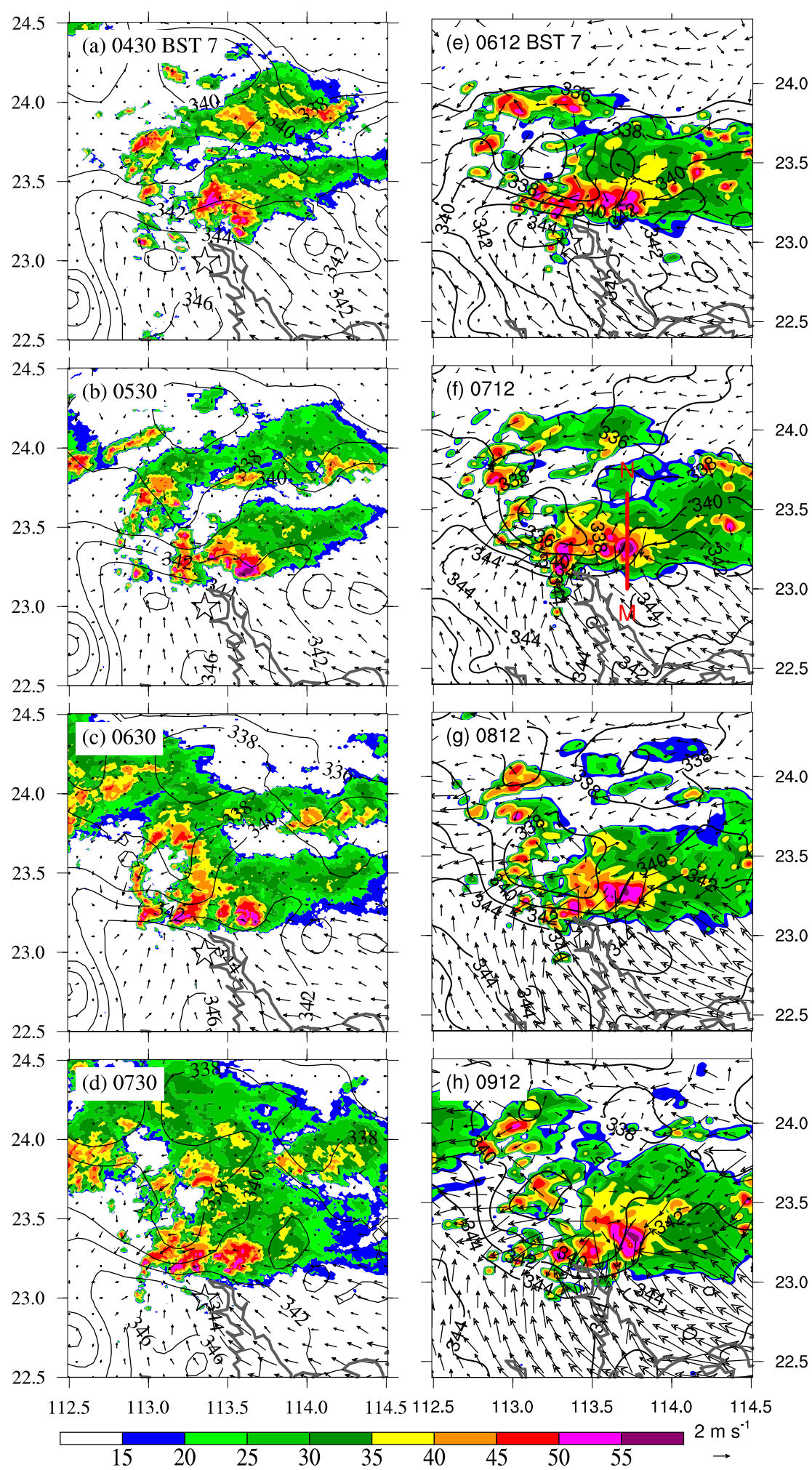

FIG. 7. As in Fig. 6, but for the development of the extreme rain-producing convective system during the period of 0430-0912 BST 7 May 2017. The red thick line, M-N in (f), indicates the location of vertical cross section used in Fig. 19. 


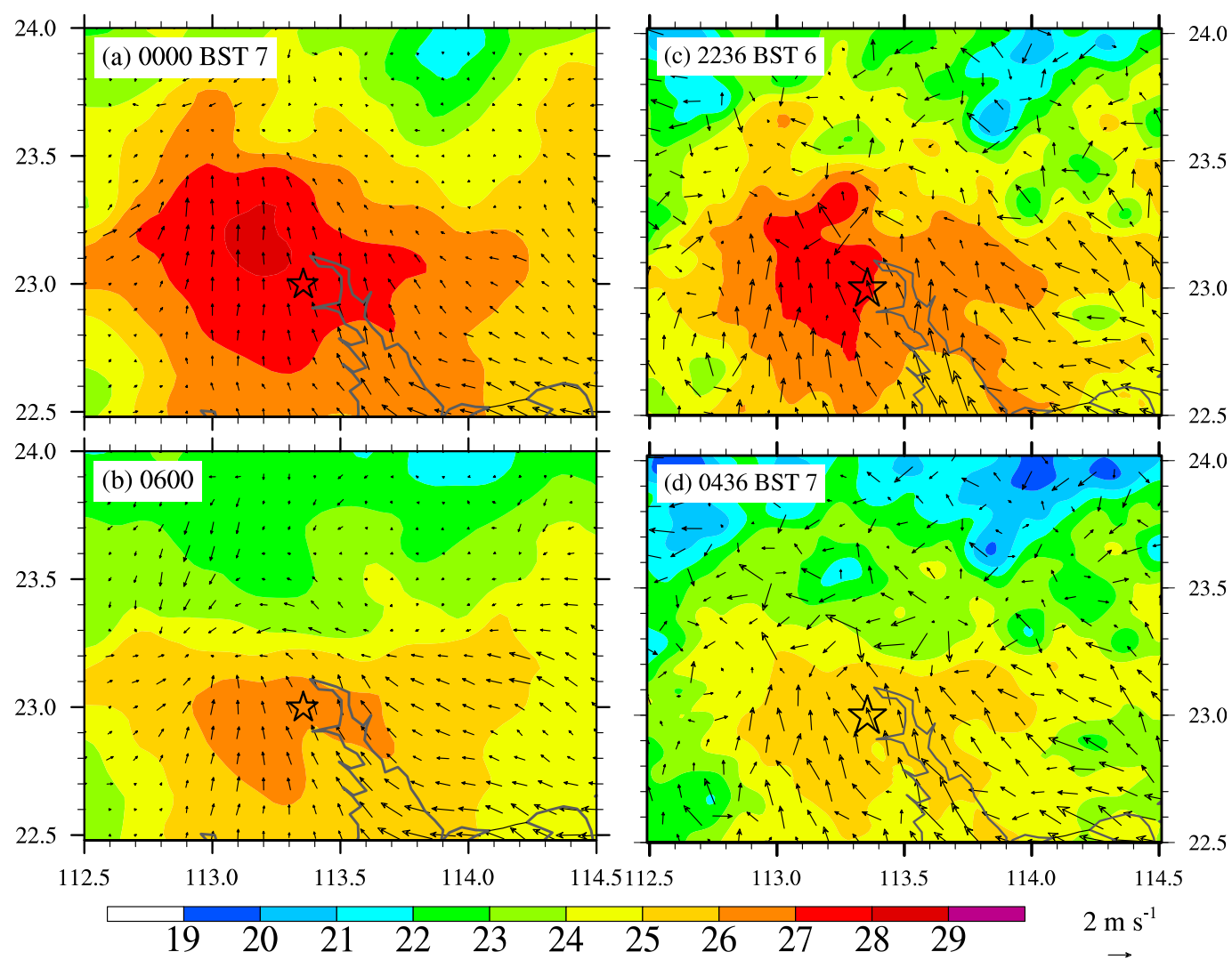

FIG. 8. Comparison of the (left) observed to the (right) simulated surface temperature $\left({ }^{\circ} \mathrm{C}\right.$, shadings) and horizontal wind vectors $\left(\mathrm{m} \mathrm{s}^{-1}\right)$ during the initial convective development stage. A reference wind vector is given beneath the right column next to the temperature color scale.

To make sure that Guangzhou's nocturnal UHI effects are reasonably represented, Fig. 8 verifies the simulated surface features against the observed during the early few hours of convective development. Note the different times used for the comparison because of the simulated 1.4-h earlier convective initiation than the observed, as shown in Figs. 5 and 6. Both the simulation and observations show the presence of the UHI effects with surface temperatures of $28^{\circ}-29^{\circ} \mathrm{C}$ over Guangzhou's $\mathrm{CBD}$ and $20^{\circ}-22^{\circ} \mathrm{C}$ in the rural area around 0000 BST 7 May (Figs. 8a,c). The observed UHI effects were still evident even during the early morning hours (Figs. 8b,d). Because of the use of surface dynamical nudging, the UHI effects remain being clearly seen up to the dawn of the second day, albeit somewhat weaker than the observed. Meanwhile, the model captures reasonably well the distinct southerly to southeasterly onshore flows, as have also been seen from Figs. 6 and 7.

Given the general agreement between the simulation and observations in terms of the timing and location in the initiation and distribution of the Huashan and Jiulong storms, we may use the convection-permitting simulation shown above to examine the roles of the UHI effects and orography in convective initiation and the roles of the onshore flows in supplying abundant moisture for the subsequent ER production in the next section. More attention will be given to the three-dimensional structures and evolution of the ER-producing Jiulong storm.

\section{Convective initiation and subsequent ER production}

\section{a. Convective initiation}

To see the impact of the UHI effects on convective initiation, Fig. 9 shows vertical cross sections of $\theta_{e}$, temperature deviations, relative humidity along the low-level onshore flow during the first 2.6-h simulation. At the initial time (i.e., after sunset), the north of Guangzhou's CBD exhibits potential instability, as indicated by negative vertical $\theta_{e}$ gradients, and the UHI effects are seen as a "warm bubble" with a temperature perturbation over $4^{\circ} \mathrm{C}$ in the lowest $300 \mathrm{~m}$ and a "high- $\theta_{e}$ air dome" in the PBL with respect to the surrounding region (Fig. 9a). Note that the peak thermal perturbation 


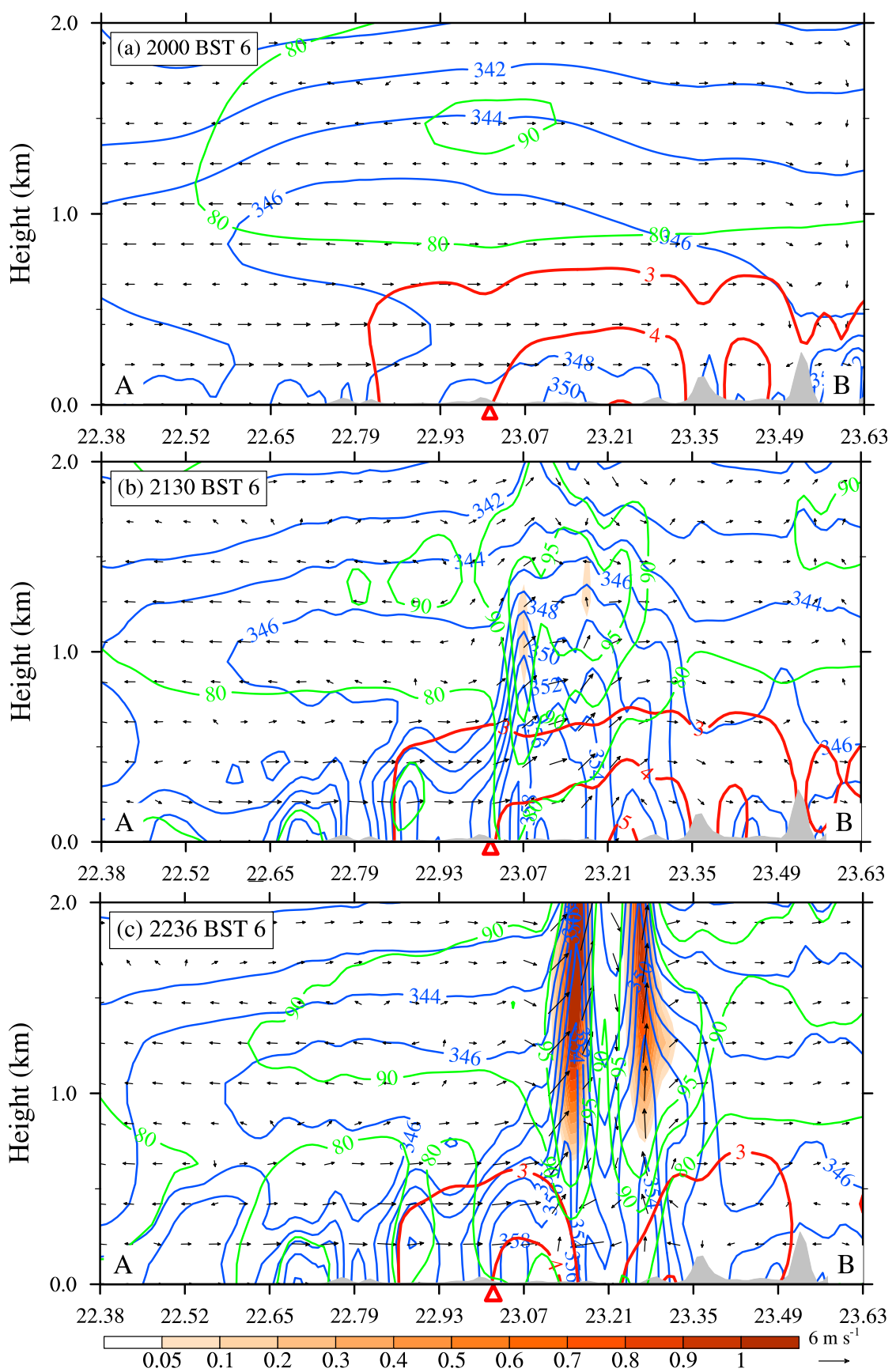

FIG. 9. Vertical cross section along line A-B given in Fig. 6e of temperature deviations (red contoured at $1^{\circ} \mathrm{C}$ intervals) from their level-averaged values in the cross section, equivalent potential temperature (blue contoured at $2 \mathrm{~K}$ intervals), relative humidity (green contoured at $10 \%$ intervals), cloud water content $\left(\mathrm{g} \mathrm{kg}^{-1}\right.$, shadings), and in-plane flow vectors (vertical motion amplified by a factor of 5) from the model initial condition (i.e., $t=0 \mathrm{~h}$ ), $t=1.5$-, and 2.6-h simulations, which are valid at (a) 2000, (b) 2130, and (c) 2236 BST 6 May 2017, respectively. Gray shadings denote terrain, and a red triangle beneath the bottom boundary indicates an approximate CBD of Guangzhou. 
has shifted to Guangzhou's downstream side due to the advective process (D.-L. Zhang et al. 2011). The vertical thermal structures are similar to the elevated PBL over the urban region of Beijing shown by Li et al. (2017a,b). The low-level convergence leading to an organized region of upward motion on Guangzhou's wake can be attributed to the increased frictional effects over the urban region, which is also similar to that shown by $\mathrm{Li}$ et al. (2017b). As a result, the warm and moist air in the PBL could be readily lifted to the LCL, forming two cloud cells in the top 1-2 km layer of the PBL at $1.5 \mathrm{~h}$ into the integration (Fig. 9b). The associated latent heat release enhances the upward motion, and the convergence of mass and moisture in the lowest layers. With the presence of little CIN (Fig. 3), it only takes $6 \mathrm{~min}$ (i.e., by 2236 BST) for the latent-heating driven updrafts of $0.5-1.0 \mathrm{~m} \mathrm{~s}^{-1}$ to develop robust clouds and precipitation even with significant compensating subsidence (Fig. 9c). The associated radar reflectivity occurring at this time represents the initiation or first appearance of the convective storms of concern, albeit with some errors in timing and location (Fig. 9c). This result indicates the importance of (i) Guangzhou's UHI and frictional effects in facilitating the initiation of deep convection in its downstream regions (Fig. 9), (ii) the continued "warm air supply" from Guangzhou's CBD to keep convectively unstable columns on the downstream (Fig. 8), and (iii) the organized southeasterly flow with a moist tongue of oceanic origin into Guangzhou City in the lowest few hundred meters (Figs. 7-9).

\section{b. Development of the Huashan storm}

Shortly after the convective initiation at the "preferred locations" from "the advective UHI effects," which will be further explored in section 5, the two convective cells grow in both size and intensity, with the half-hourly rainfall amount reaching $30 \mathrm{~mm}$ (Fig. 10a). Meanwhile, they begin to generate cold outflows, as indicated by highly divergent flow vectors, and propagate on two opposite directions with the Huashan storm moving southward. A south-north vertical cross section through the two opposite-moving centers, given in Fig. 11, shows the development of clouds in the PBL ahead of the Huashan storm, like that seen in Fig. 9, and a narrow zone (i.e., less than $0.5 \mathrm{~km}$ ) of rearward-tilted intense updrafts carrying high- $\theta_{e}$ air and evaporative-driven moist downdrafts in the trailing rainfall region. Of interest is that the updraft zone with mostly cloud water and ice leads the high reflectivity or heavy rainfall region. These appear to be more realistic structures than those seen in coarse-resolution simulations with parameterized convection showing collocated updrafts and rainfall (e.g., Zhang et al. 1989). Note that despite their

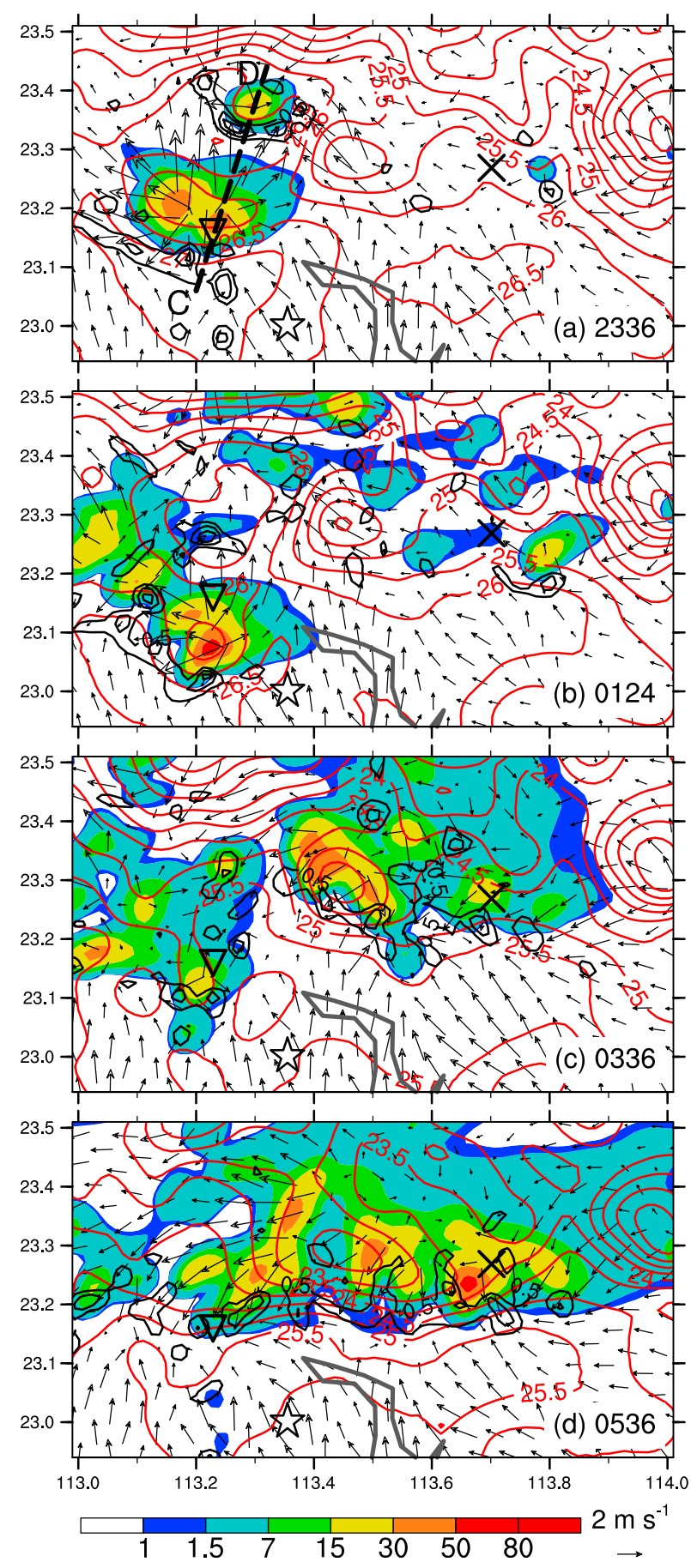

FIG. 10. Surface wind vectors and temperature (red contoured at $0.5^{\circ} \mathrm{C}$ intervals), half-hourly rainfall amount ( $\mathrm{mm}$, shadings), and upward motions of greater than $0.5 \mathrm{~m} \mathrm{~s}^{-1}$ (black contoured at $1.0 \mathrm{~m} \mathrm{~s}^{-1}$ intervals) at $0.6-\mathrm{km}$ altitude from the 3.6-, 5.4-, 7.6-, and 9.6-h simulations, which are valid at (a) 2336 BST 6 May, and (b) 0124 BST, (c) 0336 BST, and (c) 0536 BST 7 May 2017, respectively. Line $\mathrm{C}-\mathrm{D}$ in (a) denotes the location of vertical cross section used in Fig. 11. 


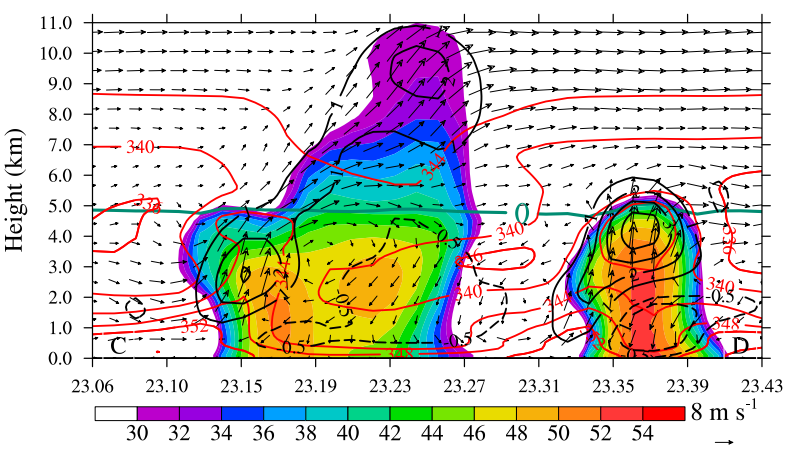

FIG. 11. Vertical cross section of radar reflectivity (dBZ, shadings), equivalent potential temperature (red contoured at $4 \mathrm{~K}$ intervals), updraft greater than $0.5 \mathrm{~m} \mathrm{~s}^{-1}$ (black solid contours) and downdraft less than $-0.5 \mathrm{~m} \mathrm{~s}^{-1}$ (black dashed contours), and inplane flow vectors (vertical motion amplified by a factor of 5) from the 3.6-h simulations, valid at 2336 BST 6 May 2017. It is taken along line $\mathrm{C}-\mathrm{D}$ marked in Fig. 10a. Thick light green line denotes an isotherm of $0^{\circ} \mathrm{C}$

different scales (i) the leading rearward-tilted intense updrafts up to the tropopause and the trailing weak updrafts above the melting level with downdrafts below resemble the conceptual model of tropical MCSs by Zipser (1977); and (ii) the development of a secondary peak reflectivity in the trailing stratiform region is similar to that shown in the two-dimensional squall line conceptual model by Houze et al. (1989).

Because of the growth of the nocturnal PBL over the rural areas, as indicated by decreased surface temperatures (Fig. 10), the northward convective expansion is suppressed despite obvious convergence along the outflow boundaries and orographical forcing. Thus, shallower convection with less rainfall occurs along the northern outflow boundaries (Figs. 10a and 11). Furthermore, for the given weak-sheared environment, convective cells developed along the outflow boundaries tend to be dragged rearward by the cold outflow induced circulations, and then dissipate in cold, stable columns (Rotunno et al. 1988; Weisman 2003). This explains well the absence of deep convection and rainfall over the central cool-pool regions (cf. Figs. 10b and 11).

Clearly, the most intense rainfall develops on the southernmost (i.e., in the Huashan storm), where both the UHI effects and the southeasterly high- $\theta_{e}$ airstream are pronounced. This storm begins to pass across Huashan around $2336 \mathrm{BST}$, and produces the peak hourly rainfall rate of $111 \mathrm{~mm} \mathrm{~h}^{-1}$ at 0136 BST (Figs. 10a,b and 5). Subsequently, the Huashan storm weakens, as it moves farther southward. This appears to be attributed partly to its moving away from the urban-induced favorable convergence region ( $\mathrm{Li}$ et al. 2017a,b), and partly to the eastward shift of the southeasterly flow axis, as mentioned before. The reduced coldness of its downdraft air originating from the lowest $\theta_{e}$ air (4-5 km altitude) layer (cf. Figs. 10a-c) could also contribute to the weakening of the Huashan storm. This can be seen from the presence of more moist layers in the midtroposphere in Hong Kong's sounding than that of Qingyuan (cf. Figs. 3a,b).

\section{c. The ER production near Jiulong}

As the high- $\theta_{e}$ tongue shifts slowly eastward, scattered convective cells start developing around a cool pool in the eastern trailing stratiform region (cf. Figs. 10a,b and $6 \mathrm{e}, \mathrm{f})$. However, these new convective cells tend to be relatively weak and short lived prior to $0300 \mathrm{BST}$ when the southeasterly energy supply is limited. Only when the more pronounced southeasterly flow appears, more intense convective cells begin to develop. This can be seen from Fig. 10c showing an intense large cell on the west of Jiulong and a weaker but intensifying one at Jiulong (i.e., the Jiulong storm) with significant rainfall [with $>15 \mathrm{~mm}(30 \mathrm{~min})^{-1}$ ]. Note the presence of distinct cold drainage flows associated with local hills on the west, east and north of the Jiulong storm (cf. Figs. 10c,d) that appears to facilitate its development through enhanced convergence with the southeasterly moist air. By 0536 BST, its half-hourly rainfall rate more than doubles while remaining quasi-stationary (Fig. 10d). Of particular interest is that the subsequent ER production occurs in a single long-lived convective cell of about $10 \mathrm{~km}$ in width, defined by the half-hourly rainfall amount of greater than $30 \mathrm{~mm}$ or the radar reflectivity of higher than $30 \mathrm{~dB} Z$. The associated processes differ significantly from the echo- or band-training processes found by many other studies of ER events occurring in South China (Luo et al. 2014; Wang et al. 2014; Wu and Luo 2016; Liu et al. 2018). Although several storms moves toward Jiulong from the west as the southeasterly high- $\theta_{e}$ tongue shifts eastward (cf. Figs. 10c,d and 7e), they dissipate before merging into the Jiulong storm. Thus, it is highly desirable in the next to examine in detail how ER takes place in such a single cell and why it is so long lived.

Figures 12-14 provide a zoomed-in view of the evolution and three-dimensional structures of the Jiulong storm over a $25 \mathrm{~km} \times 25 \mathrm{~km}$ subdomain during the period of 0600-0930 BST when its hourly rates are greater than $60 \mathrm{~mm} \mathrm{~h}^{-1}$. The meso- $\beta$-scale (i.e., $25 \mathrm{~km} \times 25 \mathrm{~km}$ ) flows surrounding the storm exhibit the general convergence of the southeasterly warm, moist air with the east- to northeasterly relatively colder air (Figs. 12a-d). The former becomes more dominant ahead of the storm during later stages (Figs. 12e,f). By comparison, the Jiulong storm remains robust as a distinct single cell located over the valley, despite the merging of a few weakening cells from the west. Of importance is the development of an arc-shaped updraft zone consisting 

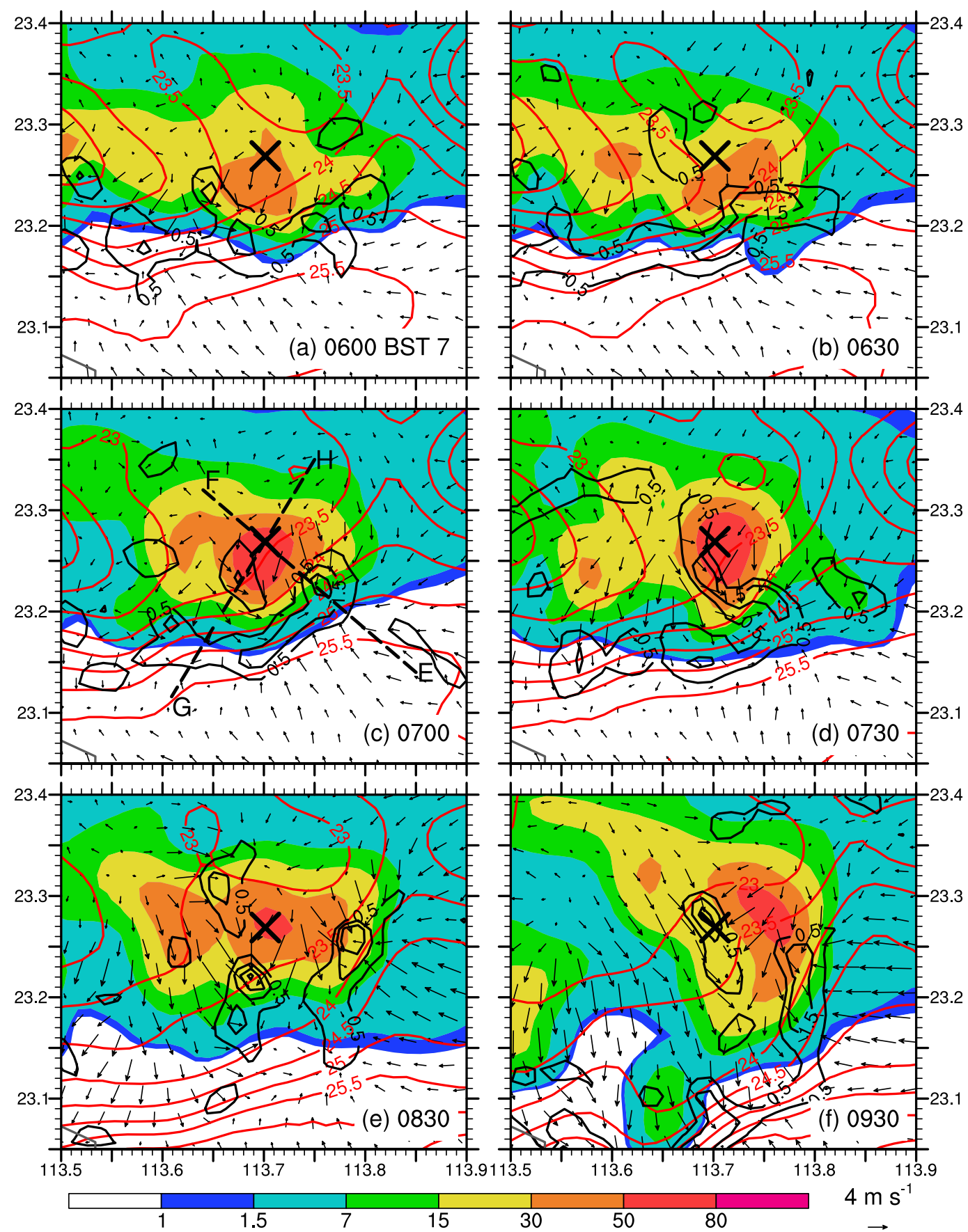

FIG. 12. As in Fig. 10, but with a zoomed-in view for the 10-13.5-h simulations during the period of 0600-0930 BST 7 May 2017. Lines E-F and G-H in (c) denote the locations of vertical cross sections used in Fig. 13.

of updrafts in the southern or southwestern semicircle of a trailing heavy rainfall region, starting from 0600 BST (Figs. 12a-d and 14b,c). This updraft structure differs from the development of a southern updraft zone associated with the Huashan storm. We may hypothesize that the arc-shaped updraft structure with a larger (total) ascending area tends to lift more moist air from the PBL for condensation than an only southern ascending area, thereby facilitating the generation of higher rainfall rates when all condensed precipitation particles fall into the same trailing region.

The collocated rainfall region from the arc-shaped updraft zone can be seen from Fig. 13 showing two vertical cross sections of radar reflectivity that are nearly 

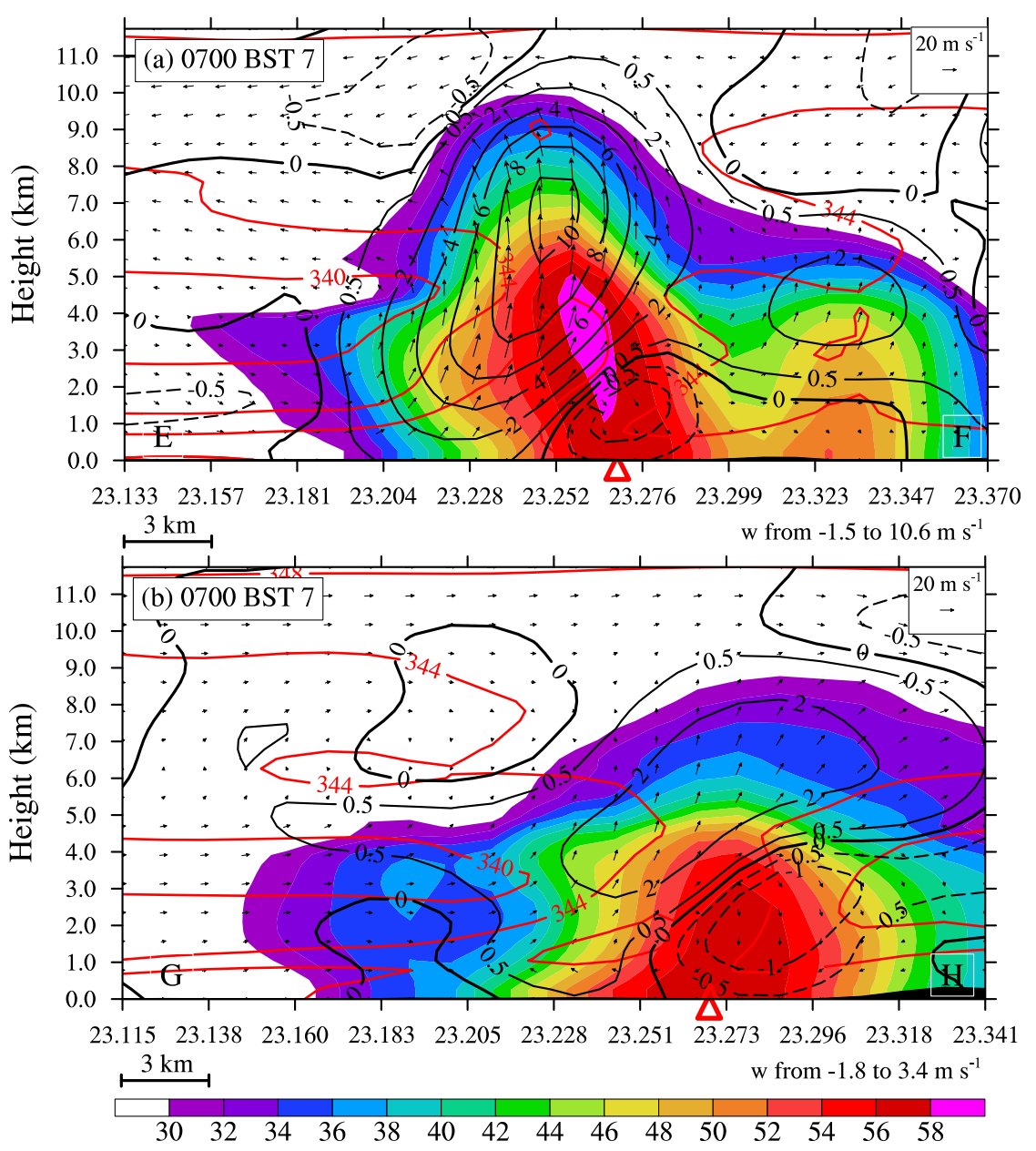

FIG. 13. Vertical cross sections along (a) E-F and (b) G-H given in Fig. 12c of the 11-h (valid at 0700 BST 07) simulated radar reflectivity (dBZ, shadings), equivalent potential temperature $\left(\theta_{e}\right.$, red contoured at $4 \mathrm{~K}$ intervals), vertical motion (thin black contoured at $2 \mathrm{~m} \mathrm{~s}^{-1}$ ) started at -0.5 and $0.5 \mathrm{~m} \mathrm{~s}^{-1}$, and in-plane flow vectors (vertical motion amplified by a factor of 5).

normal to each other across the surface rainfall center. We see the development of northward-tilted updrafts across the "frontal zone" with the peak intensity of over $10 \mathrm{~m} \mathrm{~s}^{-1}$ near 6.5 -km altitude, and downward-titled high reflectivity (or heavier rainfall) underneath the updrafts as well as a trailing stratiform region with a secondary reflectivity maximum to the northwest (Fig. 13a). Similar vertical circulation structures appear in the southwestnortheast cross section showing northeastward-tilted ascending flow in the lowest 3-km layer, albeit relatively weaker, that produce additional rainfall over the same area as those by the northwestward-tilted updrafts (cf. Figs. 13a,b). Again, this ascending flow appears to result from the convergence of southerly high- $\theta_{e}$ air into the lower pressure regions that appears to be highly influenced by local topography near Jiulong (Figs. 14b,c). This confirms our hypothesis about the important roles of the arc-shaped updraft structures in the ER production, although its rigorous validation requires a detailed water budget, which is to be presented in a future study. Little evidence of significant updrafts develops on the east of the Jiulong storm, which could be attributed to the incoming easterly flow through a large stratiform region with little conditional instability, as mentioned before. Otherwise, the rainfall rates near Jiulong could be further enhanced.

It is of further importance to note from Fig. 12 the emergence of a quasi-stationary meso- $\gamma$-scale vorte ${ }^{2}$

\footnotetext{
${ }^{2}$ A meso- $\gamma$-scale vortex is defined herein as a closed circulation with the radius of maximum wind of less than $10 \mathrm{~km}$ and the relative vorticity of at least 10 times the local Coriolis parameter, as compared to the definition of a meso- $\beta$-scale vortex by Zhang and Fritsch (1987).
} 

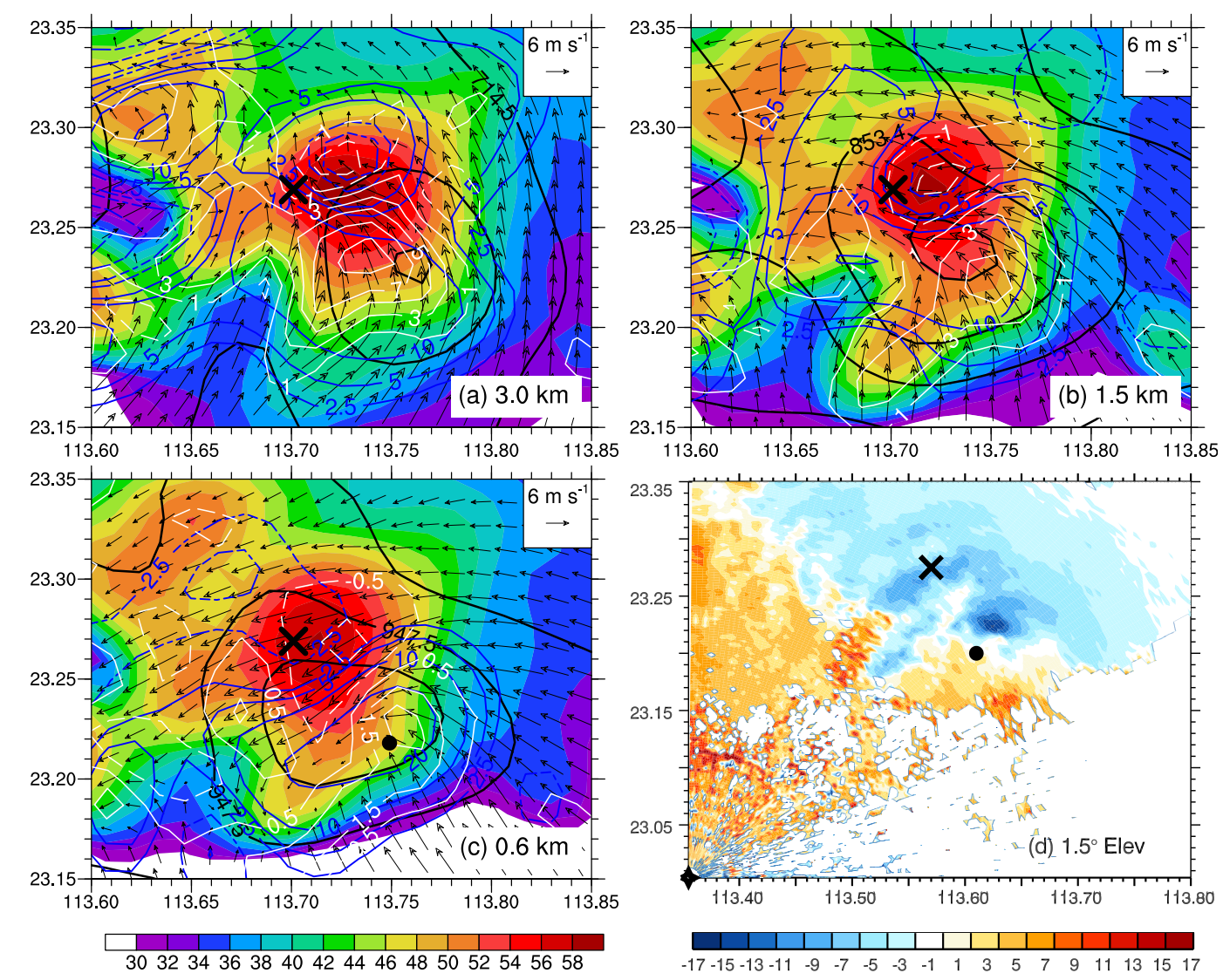

FIG. 14. The 11-h simulated pressure (black contoured at $0.5-\mathrm{hPa}$ intervals), relative vorticity (blue contoured at $10^{-4} \mathrm{~s}^{-1}$ intervals), horizontal wind vectors $\left(\mathrm{m} \mathrm{s}^{-1}\right)$, radar reflectivity ( $\mathrm{dB} Z$, shadings), and vertical motion (white contoured at $2 \mathrm{~m} \mathrm{~s}^{-1}$ intervals) associated with a meso- $\gamma$-scale vortex taken at (a) 3.0 , (b) 1.5 , and (c) $0.6 \mathrm{~km}$ altitudes, valid at 0700 BST 7 May 2017. (d) Radar radial velocity $\left(\mathrm{m} \mathrm{s}^{-1}\right)$ at $1.5^{\circ}$ elevation from Guangzhou station (located at the origin of coordinate marked with a star) at 0600 BST 7 May 2017. Black dots in (c) and (d) indicate the centers of the meso- $\gamma$-scale vortex. The bold X sign denotes the location of Jiulong.

associated with the Jiulong storm, especially during the ER period (Figs. 12e,f). This meso- $\gamma$-scale vortex has also been captured by radar observations at Guangzhou station, as given in Fig. 14d showing positive (yelloworange colored) and negative (green-blue colored) radial velocities on a tilted surface of $1.5^{\circ}$ elevation in the southern and northern semicircles of an intense cyclonic vortex, respectively. Note that the radius of the radar-observed maximum/minimum radial velocity is about $5-6 \mathrm{~km}$. The arc-shaped updraft zone and the vortex flows must be closely related, since the peak rainfall rate of $146 \mathrm{~mm} \mathrm{~h}^{-1}$ occurs during the period of 0700-0800 BST when the two features are both present (Figs. 12c-e).

It is evident from Figs. 14a-c that the pressure, vorticity and flow structures of the meso- $\gamma$-scale vortex differ from those of a midlevel meso- $\beta$-scale vortex that forms in the trailing stratiform region of MCSs (see Zhang (1992) for a review of the origin and intensification mechanism). Specifically, the meso- $\gamma$-scale vortex is peaked with the relative vorticity of more than $2 \times$ $10^{-3} \mathrm{~s}^{-1}$ near the top of cold pools (Fig. 14c), and centered in the leading convective updraft region ahead of the high reflectivity or heavy rainfall region. In the present case, the major convective updrafts occur along a quasi-stationary "frontal zone" with a thermal gradient of about $2^{\circ} \mathrm{C}(5 \mathrm{~km})^{-1}$, at which convectively generated cold outflows converge with the southeasterly flow. Clearly, it is the vortex stretching through persistent convergence along the "frontal zone" that accounts for the rapid intensification of the low-level vortex. Collocated with this vortex is a meso- $\gamma$-scale lower pressure area with a pressure deficit of $0.5-1.0 \mathrm{hPa}$ within a $5-6 \mathrm{~km}$ radius in the PBL covering both the leading updraft zone and the trailing heavy rainfall region; the radius of the pressure deficit is similar to that of the radar-observed maximum/minimum radial velocity (cf. Figs. 14b-d). The pressure deficit and vortex 
structures can be clearly seen up to $3 \mathrm{~km}$ altitude (Fig. 14a). Apparently, the presence of the pressure deficit helps enhance converging the southeasterly flow of high- $\theta_{e}$ air into the leading updraft regions and the southwesterly valley winds into the updrafts in the western portion of the Jiulong storm.

Evidently, this meso- $\gamma$-scale vortex results from the positive feedback between the low-level mass and moisture convergence, latent heat release, and increased pressure deficits, similar to that described for the development of a midlevel meso- $\beta$-scale vortex (Zhang and Fritsch 1987). We have noted an idealized modeling study of Nielsen and Schumacher (2018) who showed the collocation of extreme rainfall with meso- $\beta$-scale vortices associated with the vertical wind shear in the lowest 1-km layer. In the present case, the absorption of relative vorticity associated with the westerly merging convective cells, albeit weakening, must also contribute to the intensification of the vortex, if not directly to the ER production. The development of this meso- $\gamma$-scale vortex appears to account for the longevity of the Jiulong storm, in contrast to the Huashan storm, because of the conservative property of cyclonic vorticity in the presence of weak vertical shear.

Note that as the southeasterly flow shifts farther eastward, the arc-shaped updraft zone begins to split into two south-north-oriented updraft bands with more stratiform rainfall occurring on the south (Figs. 12d-f). Shortly after, the heavy rainfall region becomes more south-north-oriented and moves southeastward away from Jiulong into the widespread stratiform region where local "frontal" lifting is significantly reduced. In addition, energy supply decreases due to the changes of the Jiulong storm orientation with respect to the incoming high $-\theta_{e}$ airstream. Thus, the Jiulong storm weakens with time subsequently.

\section{Sensitivity simulations}

The results presented in the preceding two sections indicate the possible roles of the UHI effects and northern trumpet-shaped mountains in determining convective initiation and the subsequent development of the ER-producing storms. Thus, the following four sensitivity simulations are conducted by changing one parameter while keeping all the other model parameters identical to those used in the control results (CNTL). (i) A "warm bubble" over Guangzhou's urban area with the temperature deviations of larger than $2^{\circ} \mathrm{C}$ from Guangzhou's rural regions in the lowest 800 -m layer (see Figs. 4a and 9a) is removed from the CNTL initial conditions over domain D3, hereafter referred to as NUHI. Note that (i) the temperature deviations are obtained after subtracting the domain-3 averaged temperature at each level, and (ii) the $2^{\circ} \mathrm{C}$ temperature deviations allowed over the urban regions imply the presence of slight UHI effects at the model initial time, but much weaker than those in CNTL. Note also that there are little temperature deviations above $\sigma=0.925$ level (i.e., $z=800 \mathrm{~m}$ ) over Guangzhou's urban area. In addition, the observed surface meteorological fields are no longer nudged, except for the surface relative humidity, thereby eliminating the subsequent UHI effects to a large extent from those in CNTL. Nevertheless, the surface water vapor content has been reduced after removing the "warm bubble" by keeping the relative humidity the same as in CNTL. (ii) Like the NODA (i.e., without data assimilation) or NO-Urban (i.e., replacing urban land use with cropland) simulation of Huang et al. (2019), the initial UHI effects remain but the surface temperature field is not nudged during the model integration (NNGT). Clearly, due to the horizontal advection, the initial UHI effects could still spread downstream, though weakening rapidly with time. (iii) Latent heat release from cloud microphysical processes is turned off (NLHR), in order to gain insight into the favorable locations for convective initiation. (iv) Orography over a large area (i.e., $21.5^{\circ}-26.5^{\circ} \mathrm{N}, 109^{\circ}-116^{\circ} \mathrm{E}$ ) is removed (NTER). (This area coverage, as marked by dashed lines in Fig. 2, is much larger than the subdomain used in Figs. $16-18$ in order to isolate the UHI effects on rainfall production.)

\section{a. The UHI effects}

Figures $15 \mathrm{a}$ and $15 \mathrm{~b}$ show the vertical cross-sectional distribution of temperature deviations and $\theta_{e}$ as well as in-plane flows at about $2.6 \mathrm{~h}$ into the integrations of NUHI and NNGT, at which time convective initiation has already occurred in CNTL (see Fig. 9c). One can see that the "warm bubble" is mostly removed in the lowest $800 \mathrm{~m}$, implying the presence of reduced potential instability, albeit still $2^{\circ}-3^{\circ} \mathrm{C}$ warmer than the rural areas and $\theta_{e} \sim 354 \mathrm{~K}$ in NUHI. This is also evident in the 2.6-h simulated surface temperature field (cf. Figs. 16b and 8c). Similar scenarios appear in NNGT despite the presence of localized high- $\theta_{e}$ bubbles in the lowest 600-m layer, though with their magnitudes being weaker than those in CNTL due partly to no surface temperature nudging and partly to the negative forcing of radiative cooling in the surface layer (cf. Figs. 15b and 9c). As a result, little evidence of deep convection can be seen over and in the vicinity of Guangzhou, despite the presence of a few localized weak updraft layers downstream and near 1-km altitude in NNGT. This indicates clearly the importance of the UHI effects in generating 

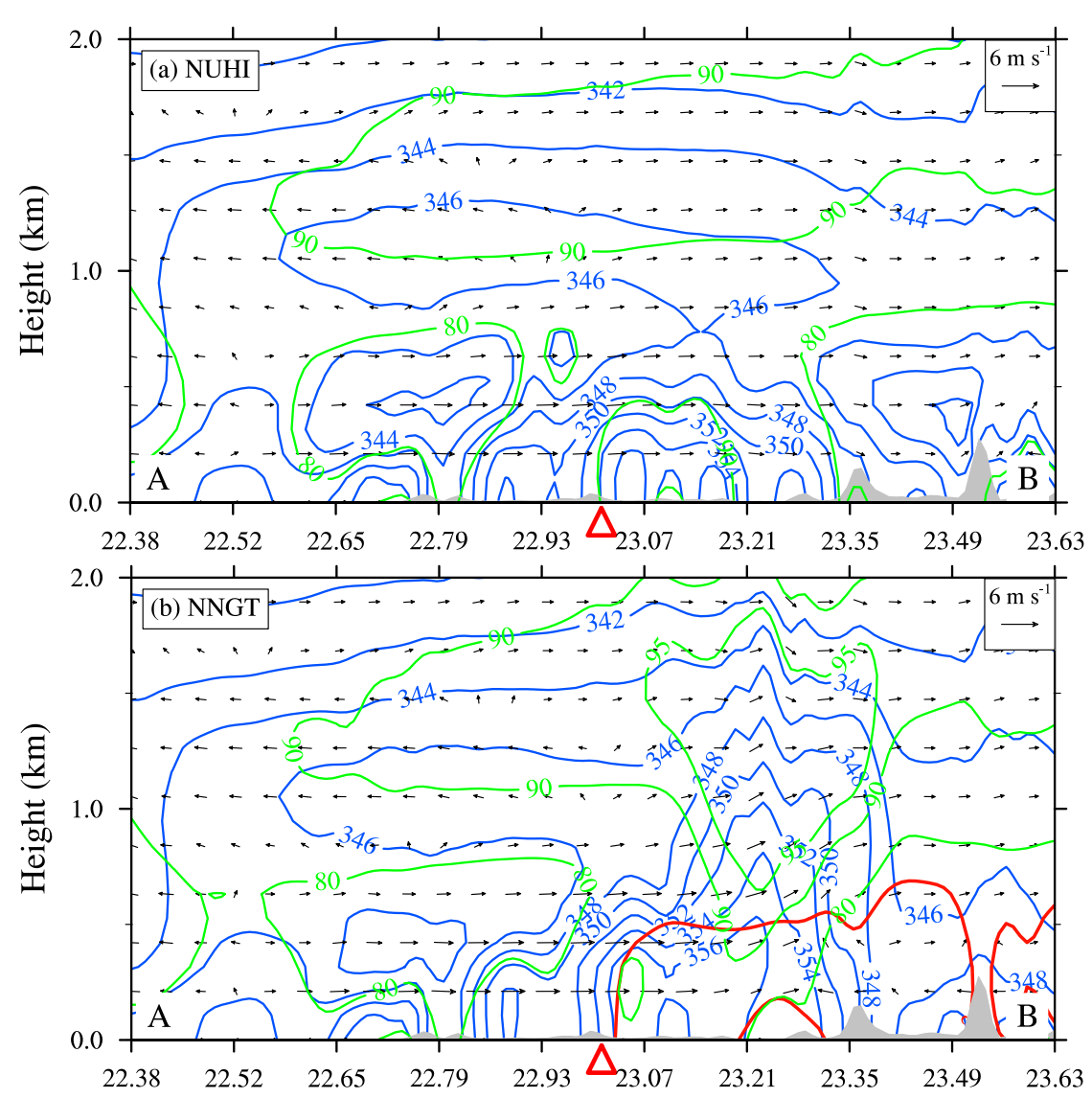

FIG. 15. As in Fig. 9c, but from the sensitivity simulation, in which (a) the UHI effects are turned off (NUHI); and (b) the initial warm bubble remains but the surface temperature is no longer nudged (NNGT).

potentially unstable conditions and eliminating CIN for possible convective initiation over the region.

The convective initiation can be illustrated through Fig. 16a showing the generation of a weak mesolow on the downstream side of Guangzhou in NLHR (and also in NNGT, not shown), where the warm bubble is located, with relatively weaker flows on the northwest and west (at $z=235 \mathrm{~m}$ ); this weak flow region is more pronounced in the surface layer in CNTL (Fig. 4a). Clearly, this mesolow is thermally generated through the advection of "hot air" from the upstream urban area. However, this mesolow is absent in NUHI (Fig. 16b), confirming the UHI effects on the formation of the mesolow. Although the thermal low is a shallow system in NLHR (and CNTL), its induced mass and moisture convergence could lift moist air to the level of condensation, eventually penetrating through the PBL inversion for convective initiation. Little such convergence could occur away from the wake region so that deep convection could only take place on the northern suburban regions of Guangzhou (e.g., Fig. 9). The flow structures are similar to the development of urban-induced wake flows found by D.-L. Zhang et al. (2019) from both observations and model simulations. Similarly, Li et al. (2017b) found that the collective effects of Beijing's CBD tend to turn an incoming flow around, accounting for increased convergence in the PBL on the downwind side for the convective initiation of an isolated thunderstorm (see Figs. 3 and 5 therein). Thus, we may state that it is the urban-induced convergence that is responsible for lifting the "buoyant" high- $\theta_{e}$ air in the suburban PBL and the subsequent appearance of the first radar echo in CNTL (Fig. 16).

By comparison, the first major radar echo in NNGT occurs at nearly the same area at that in CNTL (cf. Figs. $17 \mathrm{~d}$ and $6 \mathrm{e}$ ), but its subsequent growth in area coverage and rainfall production is much smaller than that in CNTL (cf. Figs. 17e,f, 10b, and 12c). Similarly, NNGT fails to produce the heavy rainfall belt of greater than $250 \mathrm{~m}$ from Huashan to Jiulong, with the maximum 8- and 18-h accumulated rainfall of 80 and $193 \mathrm{~mm}$ at about 20 and $35 \mathrm{~km}$ on the southwest and north of Jiulong, respectively (cf. Figs. 18c,d,a,b), and the maximum hourly rainfall rate of $68 \mathrm{~mm} \mathrm{~h}^{-1}$ (not shown). The results 


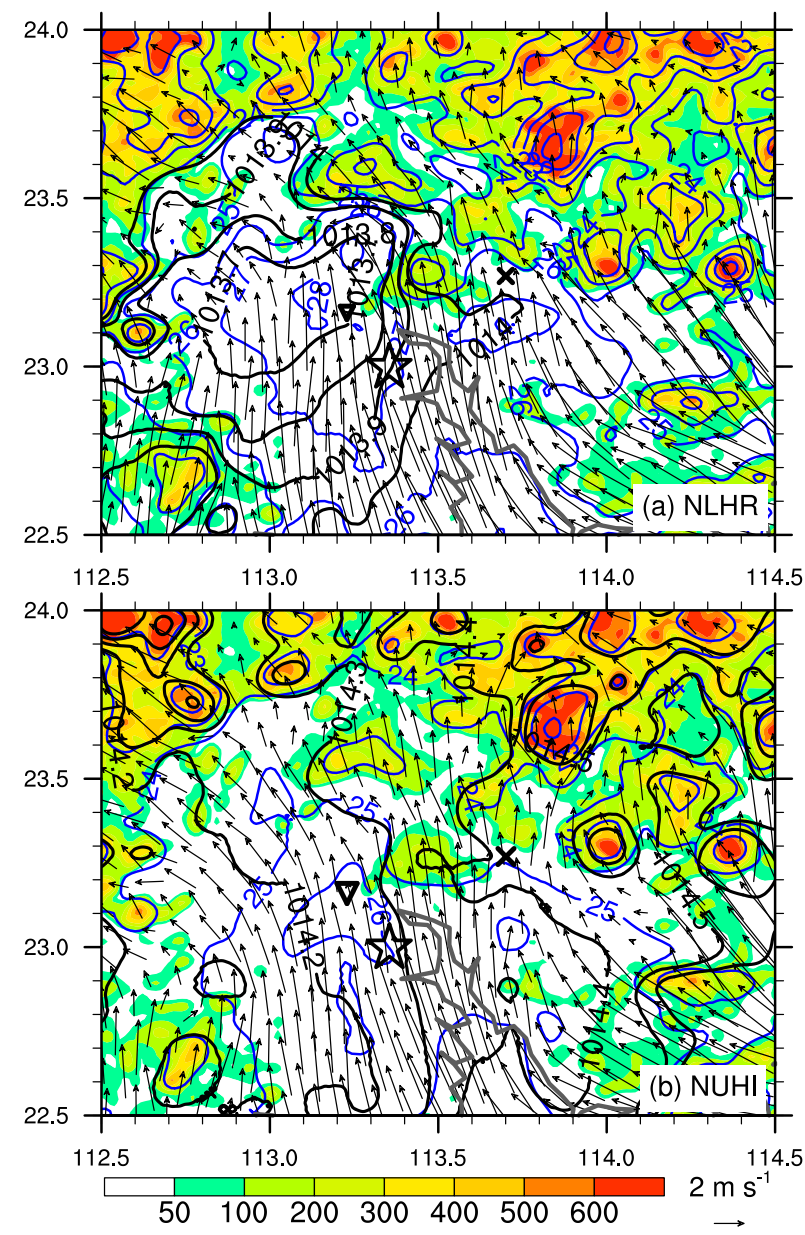

FIG. 16. Horizontal maps of sea level pressures (black contoured at $0.1 \mathrm{hPa}$ intervals), horizontal wind vectors at $\sigma=0.978$ (i.e., $z=235 \mathrm{~m}$ ), and surface temperature (at $z=2 \mathrm{~m}$, red contoured at $1^{\circ} \mathrm{C}$ intervals), superimposed with topography (color shaded) from 2.6-h (a) NLHR and (b) NUHI simulations (valid at 2236 BST 6 May 2017).

indicate clearly the importance of incorporating fully the UHI effects in producing the ER near Jiulong and the heavy rainfall $(100-250 \mathrm{~mm})$ belt from Huashan to Jiulong.

The isolated UHI effects can be better examined from NTER (Figs. 18e,f), in which a large coverage of orography is removed (Fig. 2). In spite of this extreme orographic removal, convective initiation could still take place along the southern edge of the remaining mountains northward from $26.5^{\circ} \mathrm{N}$, but at much later time than that in CNTL (not shown), and its subsequent evolution through back-building has little influences on the UHIinduced convective development. Thus, we may attribute all the rainfall amounts in NTER (i.e., Fig. 18f) to the UHI effects. Namely, the UHI effects account for the generation of heavy rainfall near Huashan, and at about $45 \mathrm{~km}$ to the northeast of Jiulong with an 18-h maximum amount of $183 \mathrm{~mm}$; this amount is about $33 \%$ of the CNTL-simulated. However, a comparison between NUHI and CNTL suggests that the UHI effects produce heavy rainfall not only on Guangzhou's downwind side, but also increase the rainfall production near Jiulong to an ER amount (i.e., from 292 to $551 \mathrm{~mm}$ ) (cf. Figs. 18b,h). Evidently, the impacts of the UHI effects, when coupled with the orographic effects of the northern mountains, on the ER production near Jiulong (i.e., the extreme amount of $551 \mathrm{~mm}$ ) are much greater than the summed local maximum amount in NUHI and NTER, implying that their coupling processes are highly nonlinear. As will be analyzed in detail in a forthcoming journal article, this result could be attributed to the formation of the quasi-stationary meso- $\gamma$-scale vortex.

\section{b. Effects of orography}

Based on the results presented above, it is necessary to examine the orographic effects on the ER production in the present case by comparing the results between NUHI, NTER, and CNTL. The early orographic effects can be seen from the diffluent east to southeasterly and south to southwesterly outflows after passing Huashan in NUHI, as compared to relatively weaker southerly to southeasterly flows in NLHR (cf. Figs. 16a,b). When meeting the northern mountains, widespread convection takes place, which explains why convective initiation could occur over the upslope region even with $\theta_{e}=338 \mathrm{~K}$, albeit until $0124 \mathrm{BST}$, as compared to that over a plain region with $\theta_{e}=344 \mathrm{~K}$ in CNTL (cf. Figs. $17 \mathrm{a}, \mathrm{b}$, and $6 \mathrm{e}$ ). Convective initiation also occurs at a plain location with $\theta_{e}=344 \mathrm{~K}$ due likely to the influences of still nudging surface winds and moisture, but about $4 \mathrm{~h}$ later than and $80 \mathrm{~km}$ to the southeast of that in CNTL. Little rainfall appears over the subdomain used in Fig. 18 in another sensitivity experiment, in which no surface-layer nudging, no UHI as in NUHI, and no terrain as in NTER are all included (not shown). This indicates that the three factors help to different degrees reproduce the timing and distribution of rainfall in CNTL. Note that the surface-layer nudging-induced storm expands slowly northeastward (cf. Figs. 17b and 18g), rather than southward as in CNTL, producing a small area of moderate rainfall amounts in the first 8-h integrations (cf. Figs. 18a,g). This storm merges with the northwesterly convective elements forced by the northern sloping mountains (cf. Figs. 17c and 16b), thereby forming a back-building convective system. By the end of the 18-h integration, NUHI produces a significant area of 100-250 $\mathrm{mm}$ rainfall near Jiulong, with the maximum amount of $292 \mathrm{~mm}$ at about $20 \mathrm{~km}$ to the east, as compared to the NTER-generated maximum amount of $183 \mathrm{~mm}$ (cf. Figs. 18f,h). Thus, in the absence of the UHI 


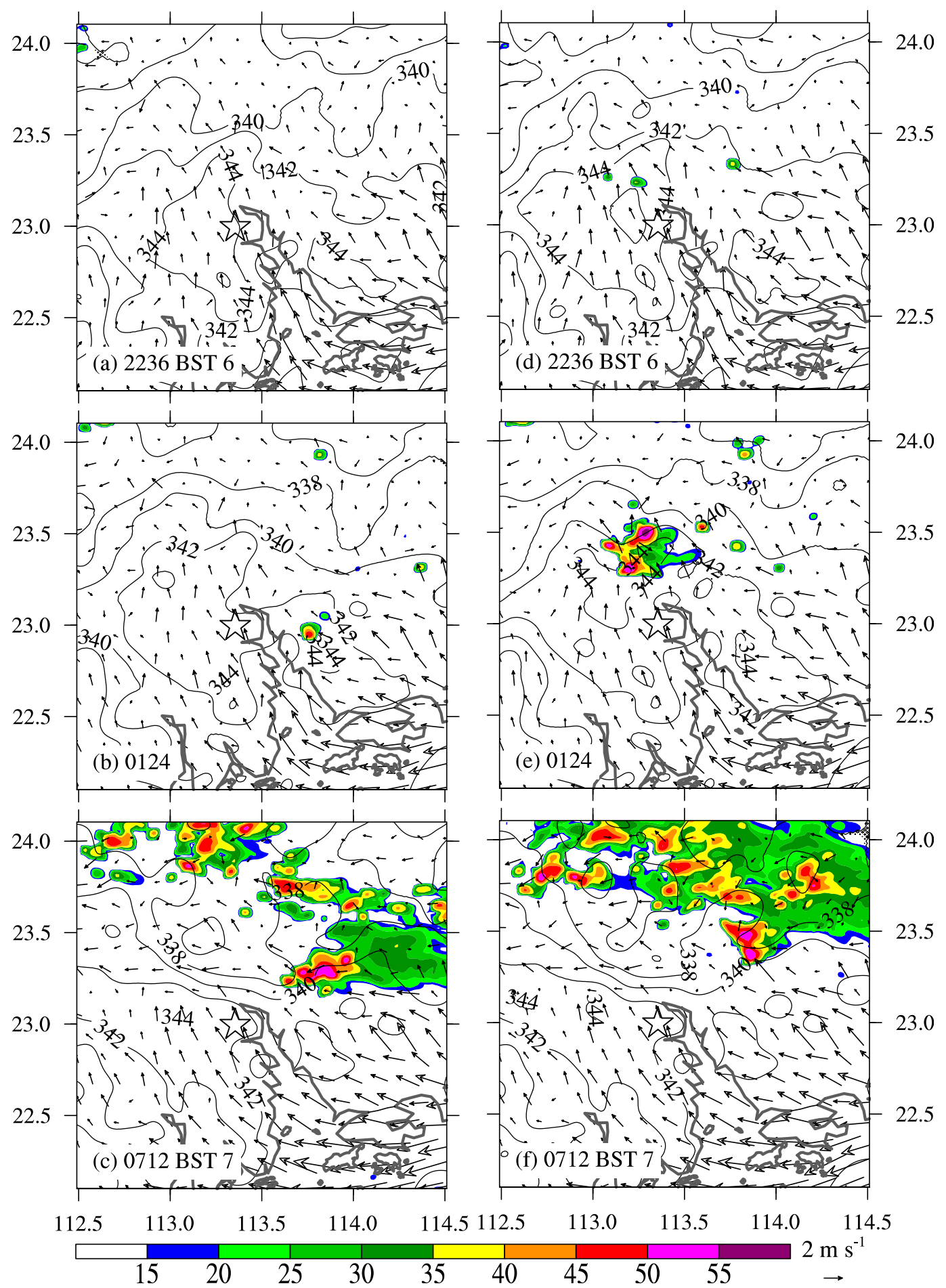

FIG. 17. As in Fig. 6, but for the sensitivity simulations, in which (a)-(c) the UHI effects are turned off (NUHI), and (d)-(f) the initial warm bubble remains but the surface temperature is no longer nudged (NNGT), that are valid at (a),(d) 2236 BST 6 May; (b),(e) 0124 BST 7 May; and (c),(f) 0700 BST 7 May 2017, respectively. 

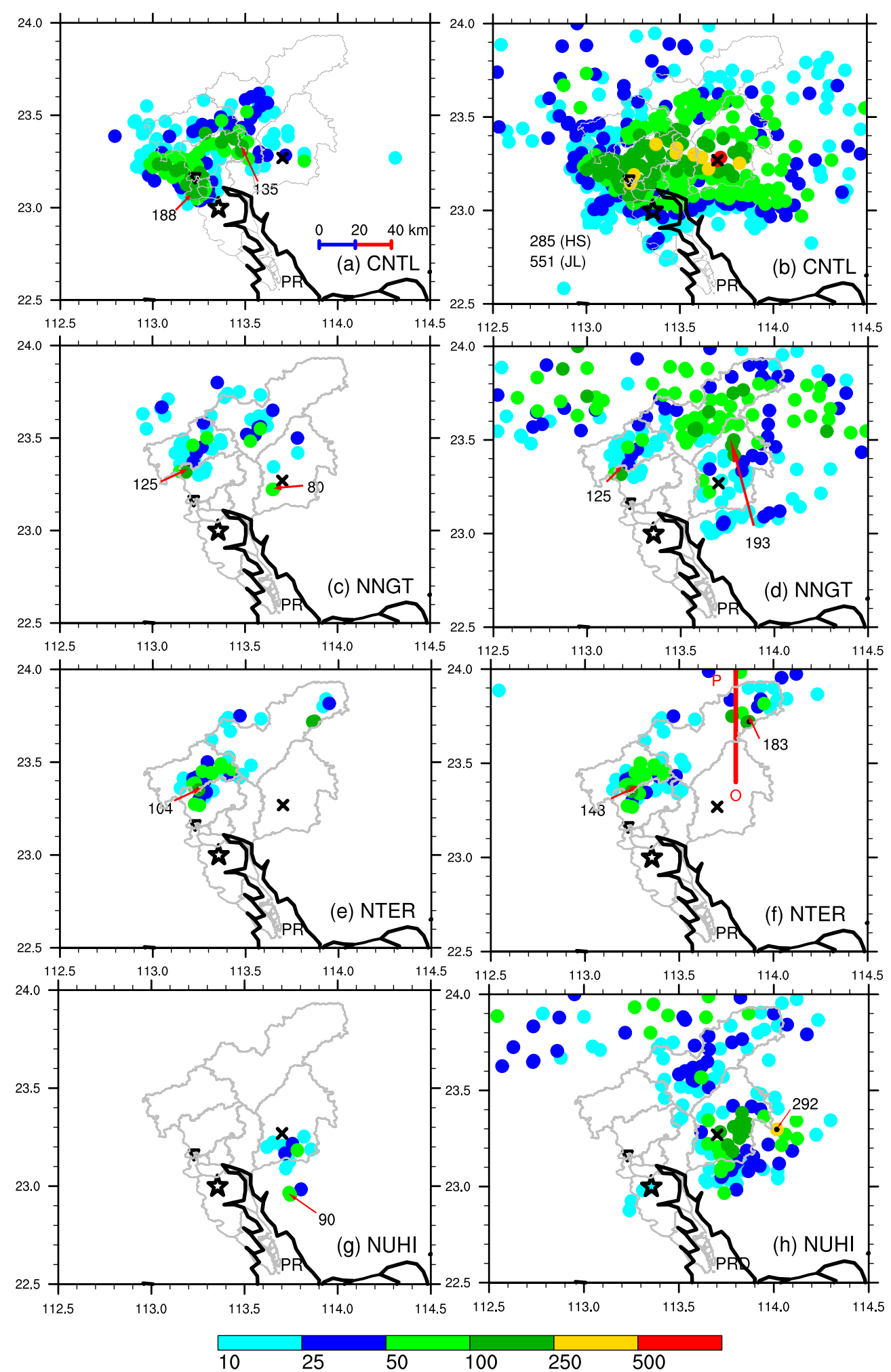

FIG. 18. The accumulated rainfall amounts during (left) the first 8-h integrations and (right) the 18-h integrations associated with (a),(b) CNTL, (c),(d) NNGT, (e),(f) NTER, and (g),(h) NUHI. The maximum rainfall amounts near Huashan and Jiulong are also given. 

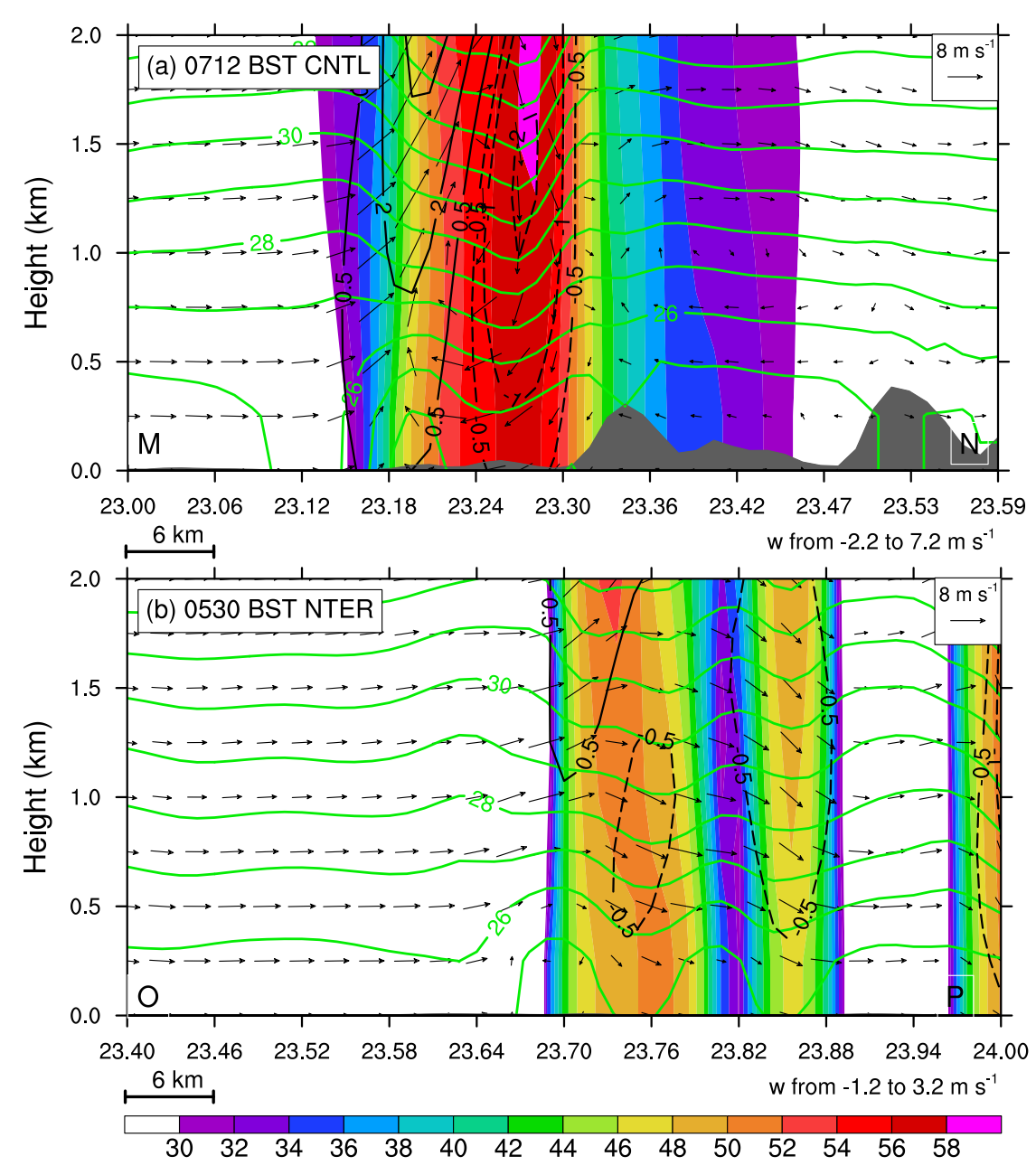

FIG. 19. Comparison of the vertical cross sections of potential temperature ( $\theta$, green contoured at $1^{\circ} \mathrm{C}$ intervals) and in-plane flow vectors (vertical motion amplified by a factor of 5) superimposed with radar reflectivity ( $\mathrm{dBZ}$, shadings) between (a) the 11.2-h control simulation (valid at 0712 BST 7 May), taken along line M-N (i.e., 113.72 ${ }^{\circ}$ ) in Fig. 7f, and (b) the 9.5-h NTER simulation (valid at 0530 BST 7 May), taken along line O-P (i.e., 113.8 ${ }^{\circ}$ ) in Fig. 18f. Note that both panels are taken near the times when heavy rainfall occurs.

effects orography could only produce $53 \%$ of the CNTLsimulated maximum rainfall near Jiulong (Fig. 18h).

While the relatively larger contribution of the maximum rainfall in NUHI than that in NTER near Jiulong seems to support the major conclusion of Huang et al. (2019), it is important to realize the different roles of orography in NUHI from those in CNTL that may help understand the abovementioned nonlinear urban-orographic coupling processes, given the ample large-scale moisture supply. That is, the northern mountains in NUHI play a role in convective initiation when interacting with the southerly high- $\theta_{e}$ air, and then in blocking convectively generated cold outflows such that heavy rainfall could take place in northeastern Guangzhou through the back-building process. In contrast, the northern mountains in CNTL tend to block convectively generated cold outflows by the UHI-induced storms. This can be seen by comparing the results between CNTL and NTER. That is, the CNTL run shows significant lifting occurring at the (northerly) cold outflow boundary of about $1 \mathrm{~km}$ depth on the south of the northern mountains with little outflow on the north (Fig. 19a). By comparison, the NTER run exhibits little lifting at the southern edge of the cold pool with little (northerly) outflow, but pronounced (southerly) outflow on the northern side of deep convection (Fig. 19b). This explains why convective storms could not be advanced into the Jiulong region in NTER (cf. Figs. 18f,b), due to the absence of the orographic blocking effects of convectively generated cold pools. Moreover, while the northern mountains play an important role in both facilitating convective initiation and blocking the cold pool 
in NUHI (Figs. 17a-c), few convective cells (i.e., with $>35 \mathrm{dBZ}$ ) are initiated near the northern mountains (i.e., to the north of $23.5^{\circ} \mathrm{N}$ ) in CNTL (Figs. 6e-h and $7 \mathrm{e}-\mathrm{h})$. These results confirm the important roles of the northern mountains in helping magnify the rainfall production near Jiulong in CNTL by enhancing the convectively generated cold pool strength.

It should be mentioned that neither NTER or NNGT produces a meso- $\gamma$-scale vortex in the vicinity of Jiulong or heavy rainfall regions during the 18 -h simulations. This suggests further the correlation between the ER production and the meso- $\gamma$-scale vortex, and some possible roles of the latter in generating ER near Jiulong. This will be explored in a forthcoming journal article.

\section{Summary and conclusions}

In this study, we examine the impact of the UHI effects and orography on the convective initiation and subsequent ER generation over the southern coastal city of Guangzhou during the nocturnal period of 7 May 2017 using a series of cloud-permitting simulations with the WRF Model. Results from the control simulation, in which the observed surface winds, temperature and relative humidity are nudged, show that the model reproduces convective initiation on Guangzhou's downstream side (i.e., near Huashan) where a shallow thermal mesolow due to the advection of the UHI effects is located. Both the model simulation and observations show that new convective cells continuously form along the leading edge of a convectively generated cold pool through back-building, as the southerly warm and moist flow interacts with the cold pool, and then organize into a meso- $\beta$-scale convective system with pronounced trailing stratiform rainfall. The leading convective cells are arc-shaped on the western edge of the cold pool during the earlier development stages. After dropping heavy rain near Huashan, they become more zonally oriented and move slowly eastward as the axis of the southerly higher- $\theta_{e}$ airstream in the PBL drifts eastward.

Of particular significance is that the model reproduces the heavy and extreme rainfall episodes near Huashan and Jiulong, respectively. That is, the model produces the total accumulated rainfall amount of $285 \mathrm{~mm}$ with the maximum hourly rate of $111 \mathrm{~mm} \mathrm{~h}^{-1}$ near Huashan compared to the corresponding observed amount of $341 \mathrm{~mm}$ with the maximum hourly rate of $120 \mathrm{~mm} \mathrm{~h}^{-1}$; and the total accumulated rainfall amount of $551 \mathrm{~mm}$ with the maximum hourly rates of $146 \mathrm{~mm} \mathrm{~h}^{-1}$ near Jiulong compared to the corresponding observed values of $542 \mathrm{~mm}$ with the extreme hourly rates of $184 \mathrm{~mm} \mathrm{~h}^{-1}$.
Of further significance is that the model reproduces an observed quasi-stationary meso- $\gamma$-scale vortex with the relative vorticity of greater than $2 \times 10^{-3} \mathrm{~s}^{-1}$, which is centered in the leading updrafts of the Jiulong storm. Although it remains to be validated through budget calculations in a future journal article, we believe that it is this quasi-stationary vortex that allow for the sustained development of convective updrafts along cold outflows over a semicircle, thereby leading to the generation of ER near Jiulong.

Sensitivity simulations are performed to examine the relative roles of the UHI effects and orography in determining the convective initiation and subsequent generation of heavy rainfall near Huashan, ER near Jiulong, and the regional rainfall amounts and coverage. Results confirm the importance of the UHI effects in generating potentially unstable conditions and eliminating CIN with a mesolow on Guangzhou's downwind side, which in turn facilitate convective initiation and heavy rainfall production near Huashan. Removing the UHI effects (i.e., in NUHI) isolates the roles of orography in convective initiation as the southerly high- $\theta_{e}$ air meets the northern mountains, and then in blocking convectively generated cold outflows for the heavy rainfall generation near Jiulong through the back-building process. However, the coupling of the UHI with orographic effects appears to be highly nonlinear in the generation of ER near Jiulong, when the results from NUHI, NTER and CNTL are compared. That is, the ER amount of $551 \mathrm{~mm}$ in CNTL is much greater than the summed maximum rainfall accumulated near Jiulong from NUHI and NTER. This result reveals the nonlinear aspects of rainfall production after forming the quasi-stationary meso- $\gamma$-scale vortex as a result of the coupling of the UHI effects with the orographic effects of the northern mountains. In this case, orography acts to block convectively generated cold outflows and enhance cool pool strength, thereby allowing the sustained back building of deep convection around the enhanced cold outflows.

In conclusion, given the ample southerly moisture supply in the PBL, the UHI effects determine the convective initiation and subsequent heavy rainfall production near Huashan, and account indirectly for the formation of the Jiulong storm, whereas the northern mountains play a role in blocking the cold outflows for the sustained back-building of the ER-producing storm near Jiulong. These results have important implications to understanding how urbanization alters convective initiation and the subsequent regional heavy rainfall distribution, and to what extent the urban-induced convective storms interact with nearby orographic forcing to determine the local generation and regional 
distribution of ER production. In a forthcoming journal article, a diagnostic and budget study will be performed to examine how the quasi-stationary meso- $\gamma$-scale vortex, interacting with the low-level southerly high $\theta_{e}$ air and the enhanced cold outflows, determines the generation of the ER rate of $146 \mathrm{~mm} \mathrm{~h}^{-1}$ near Jiulong. As a final remark, we should mention a limitation of this modeling study, namely, the nocturnal UHI effects have to be included by nudging surface observations. Thus, further studies with the coupled WRF/multi-layer urban canopy model (e.g., see D.-L. Zhang et al. 2019) are needed to examine to what extent the nocturnal UHI effects could be reproduced by initializing it at a morning hour and then integrating it over a diurnal cycle.

Acknowledgments. This study is jointly supported by the National Key Research and Development Program of China (2018YFC1507400, 2018YFC1507404, and 2017YFC1501806), and Development Foundation of Chinese Academy of Meteorological Sciences (2017Z006, and 2019KJ026).

\section{REFERENCES}

Angevine, W. M., A. B. White, C. J. Senff, M. Trainer, R. M. Banta, and M. A. Ayoub, 2003: Urban-rural contrasts in mixing height and cloudiness over Nashville in 1999. J. Geophys. Res., 108, 4092, https://doi.org/10.1029/2001JD001061.

Arnfield, A. J., 2003: Two decades of urban climate research: A review of turbulence, exchanges of energy and water, and the urban heat island. Int. J. Climatol., 23, 1-26, https://doi.org/ 10.1002/joc.859.

Battan, L. J., 1973: Radar Observation of the Atmosphere. The University of Chicago Press, 324 pp.

Bornstein, R., and Q. Lin, 2000: Urban heat islands and summertime convective thunderstorms in Atlanta: Three case studies. Atmos. Environ., 34, 507-516, https://doi.org/10.1016/S13522310(99)00374-X.

Braham, R. R., Jr., R. G. Semonin, A. H. Auer, S. A. Changnon Jr., and J. M. Hales, 1981: Summary of urban effects on clouds and rain. METROMEX: A Review and Summary, Meteor. Monogr., No. 40, Amer. Meteor. Soc., 141-152.

Debbage, N., and J. M. Shepherd, 2019: Urban influences on the spatiotemporal characteristics of runoff and precipitation during the 2009 Atlanta flood. J. Hydrometeor., 20, 3-21, https://doi.org/10.1175/JHM-D-18-0010.1.

Garuma, G. F., 2018: Review of urban surface parameterizations for numerical climate models. Urban Climate, 24, 830-851, https://doi.org/10.1016/j.uclim.2017.10.006.

Hong, S.-Y., Y. Noh, and J. Dudhia, 2006: A new vertical diffusion package with an explicit treatment of entrainment processes. Mon. Wea. Rev., 134, 2318-2341, https://doi.org/ 10.1175/MWR3199.1.

Houze, R. A., S. A. Rutledge, M. I. Biggerstaff, and B. F. Smull, 1989: Interpretation of Doppler weather radar displays of midlatitude mesoscale convective systems. Bull. Amer. Meteor. Soc., 70, 608-619, https://doi.org/10.1175/1520-0477(1989) $070<0608$ :IODWRD>2.0.CO;2.
Huang, S., 1986: Heavy Rainfall of South China in Early-Summer Flood Season (in Chinese). Guangdong Science and Technology Press, 244 pp.

Huang, Y., Y. Liu, Y. Liu, H. Li, and J. C. Knievel, 2019: Mechanisms for a record-breaking rainfall in the coastal metropolitan city of Guangzhou, China: Observation analysis and nested very large eddy simulation with the WRF model. J. Geophys. Res. Atmos., 124, 1370-1391, https://doi.org/ 10.1029/2018JD029668.

Kain, J. S., 2004: The Kain-Fritsch convective parameterization: An update. J. Appl. Meteor., 43, 170-181, https://doi.org/ 10.1175/1520-0450(2004)043<0170:TKCPAU > 2.0.CO;2.

Li, H., X. Cui, and D.-L. Zhang, 2017a: On the initiation of an isolated heavy-rain-producing storm near the central urban area of the Beijing metropolitan region. Mon. Wea. Rev., 145, 181-197, https://doi.org/10.1175/MWR-D-16-0115.1.

- —, and,$- 2017 \mathrm{~b}$ : Sensitivity of the initiation of an isolated thunderstorm over the Beijing metropolitan region to urbanization, terrain morphology and cold outflows. Quart. J. Roy. Meteor. Soc., 143, 3153-3164, https://doi.org/ 10.1002/qj.3169.

Liang, P., and Y. H. Ding, 2017: The long-term variation of extreme heavy precipitation and its link to urbanization effects in Shanghai during 1916-2014. Adv. Atmos. Sci., 34, 321-334, https://doi.org/10.1007/s00376-016-6120-0.

Liu, X., Y. Luo, Z. Guan, and D.-L. Zhang, 2018: An extreme rainfall event in coastal South China during SCMREX-2014: Formation and roles of rainband and echo trainings. J. Geophys. Res. Atmos., 123, 9256-9278, https://doi.org/10.1029/ 2018JD028418.

Lo, J. C. F., A. K. Lau, F. Chen, J. C. Fung, and K. K. Leung, 2007: Urban modification in a mesoscale model and the effects on the local circulation in the Pearl River Delta Region. J. Appl. Meteor. Climatol., 46, 457-476, https://doi.org/10.1175/ JAM2477.1.

Luo, Y., 2017: Advances in understanding the early-summer heavy rainfall over South China. The Global Monsoon System, C. P. Chang et al., Eds., World Scientific Series on Asia-Pacific Weather and Climate, Vol. 9, 215-226.

_ Y. Y. Gong, and D.-L. Zhang, 2014: Initiation and organizational modes of an extreme-rain-producing mesoscale convective system along a Mei-Yu front in East China. Mon. Wea. Rev., 142, 203-221, https://doi.org/10.1175/MWR-D-13-00111.1.

—_, and Coauthors, 2017: The Southern China Monsoon Rainfall Experiment (SCMREX). Bull. Amer. Meteor. Soc., 98, 999-1013, https://doi.org/10.1175/BAMS-D-15-00235.1.

Mlawer, E. J., S. J. Taubman, P. D. Brown, M. J. Iacono, and S. A. Clough, 1997: Radiative transfer for inhomogeneous atmospheres: RRTM, a validated correlated-k model for the longwave. J. Geophys. Res., 102, $16663-16682$, https://doi.org/ 10.1029/97JD00237.

Nielsen, E. R., and R. S. Schumacher, 2018: Dynamical insights into extreme short-term precipitation associated with supercells and sesovortices. J. Atmos. Sci., 75, 2983-3009, https://doi.org/ 10.1175/JAS-D-17-0385.1.

Niu, G.-Y., and Coauthors, 2011: The community Noah land surface model with multiparameterization options (Noah-MP): 1. Model description and evaluation with local-scale measurements. J. Geophys. Res., 116, D12109, https://doi.org/10.1029/ 2010JD015139.

Oke, T. R., 1987: Boundary Layer Climates. 2nd ed. Methuen, 435 pp. Reen, B., 2016: A brief guide to observation nudging in WRF. Battlefield Environment Division, Army Research 
Laboratory, 34 pp., www2.mmm.ucar.edu/wrf/users/docs/ ObsNudgingGuide.pdf.

Rotunno, R., J. B. Klemp, and M. L. Weisman, 1988: A theory for strong, long-lived squall lines. J. Atmos. Sci., 45, 463-485, https://doi.org/10.1175/1520-0469(1988)045<0463:ATFSLL> 2.0.CO;2.

Schumacher, R. S., T. J. Galarneau, and L. F. Bosart, 2011: Distant effects of a recurving tropical cyclone on rainfall in a midlatitude convective system: A high-impact predecessor rain event. Mon. Wea. Rev., 139, 650-667, https://doi.org/10.1175/ 2010MWR3453.1.

Seaman, N. L., D. R. Stauffer, and A. M. Lario-Gibbs, 1995: A multiscale four-dimensional data assimilation system applied in the San Joaquin Valley during SARMAP. Part I: Modeling design and basic performance characteristics. J. Appl. Meteor., 34, 1739-1761, https://doi.org/10.1175/ 1520-0450(1995)034<1739:AMFDDA > 2.0.CO;2.

Shepherd, J. M., 2005: A review of current investigation of urbaninduced rainfall and recommendations for the future. Earth Interact., 9, https://doi.org/10.1175/EI156.1.

Skamarock, W. C., and Coauthors, 2008: A description of the Advanced Research WRF version 3. NCAR Tech. Note NCAR/TN-475+STR, 113 pp., https://doi.org/10.5065/ D68S4MVH .

Stauffer, D. R., and N. L. Seaman, 1990: Use of four-dimensional data assimilation in a limited-area mesoscale model. Part I: Experiments with synoptic-scale data. Mon. Wea. Rev., 118, 1250-1277, https://doi.org/10.1175/1520-0493(1990)118<1250: UOFDDA $>2.0 . \mathrm{CO} ; 2$

Thompson, G., P. R. Field, R. M. Rasmussen, and W. D. Hall, 2008: Explicit forecasts of winter precipitation using an improved bulk microphysics scheme. Part II: Implementation of a new snow parameterization. Mon. Wea. Rev., 136, 5095-5115, https://doi.org/10.1175/2008MWR2387.1.

Wang, D., and Coauthors, 2015: Urban extent enhances extreme precipitation over the Pearl River Delta, China. Atmos. Sci. Lett., 16, 310-317, https://doi.org/10.1002/asl2.559.

Wang, H., Y. Luo, and J. D. Jou Ben, 2014: Initiation, maintenance, and properties of convection in an extreme rainfall event during SCMREX: Observational analysis. J. Geophys. Res. Atmos. 119, 13 206-13 232, https://doi.org/10.1002/2014JD022339.

Wang, W., and Coauthors, 2017: User's guides for the Advanced Research WRF (ARW) modeling system. Accessed 17 July 2017, http://www2.mmm.ucar.edu/wrf/users/docs/ user_guide_V3/contents.html.

Weisman, M. L., 2003: Convective storms: Overview. Encyclopedia of Atmospheric Sciences, J. R. Holton, Ed., Academic Press, 548-559.

Wu, J.-B., and Coauthors, 2011: Urban heat island effects of the Pearl River Delta city clusters-Their interactions and seasonal variation. Theor. Appl. Climatol., 103, 489-499, https:// doi.org/10.1007/s00704-010-0323-6.

Wu, M., and Y. Luo, 2016: Mesoscale observational analysis of lifting mechanism of a warm-sector convective system producing the maximal daily precipitation in China Mainland during presummer rainy season of 2015. J. Meteor. Res., 30, 719-736, https://doi.org/10.1007/s13351-016-6089-8.

, - _ F. Chen, and W. K. Wong, 2019: Observed link of extreme hourly precipitation changes to urbanization over coastal South China. J. Appl. Meteor. Climatol., 58, 1799-1819, https://doi.org/10.1175/JAMC-D-18-0284.1.

Yin, J.-F., and Coauthors, 2018: Numerical study of the role of microphysical latent heating and surface heat fluxes in a severe precipitation event in the warm sector over southern China. Asia-Pac. J. Atmos. Sci., 54, 77-90, https://doi.org/10.1007/ s13143-017-0061-0.

Yu, M., and Y. Liu, 2015: The possible impact of urbanization on a heavy rainfall event in Beijing. J. Geophys. Res. Atmos., 120, 8132-8143, https://doi.org/10.1002/2015JD023336.

Zhang, D.-L., 1992: The formation of a cooling-induced mesovortex in the trailing stratiform region of a midlatitude squall line. Mon. Wea. Rev., 120, 2763-2785, https://doi.org/10.1175/ 1520-0493(1992)120<2763:TFOACI >2.0.CO;2.

— , and R. A. Anthes, 1982: A high-resolution model of the planetary boundary layer-Sensitivity tests and comparisons with SESAME-79 data. J. Appl. Meteor., 21, 1594-1609, https://doi.org/10.1175/1520-0450(1982)021<1594:AHRMOT> 2.0.CO;2.

, and J. M. Fritsch, 1987: Numerical simulation of the meso- $\beta$ scale structure and evolution of the 1977 Johnstown Flood. Part II: Inertially stable warm-core vortex and the mesoscale convective complex. J. Atmos. Sci., 44, 2593-2612, https://doi.org/ 10.1175/1520-0469(1987)044<2593:NSOTMS>2.0.CO;2.

_- K. Gao, and D. B. Parsons, 1989: Numerical simulation of an intense squall line during 10-11 June 1985 PRE-STORM. Part I: Model verification. Mon. Wea. Rev., 117, 960-994, https://doi.org/10.1175/1520-0493(1989)117<0960:NSOAIS > 2.0.CO;2.

_ _ Y. Shou, R. R. Dickerson, and F. Chen, 2011: Impact of upstream urbanization on the urban heat island effects along the Washington-Baltimore corridor. J. Appl. Meteor. Climatol., 50, 2012-2029, https://doi.org/10.1175/JAMC-D10-05008.1.

_ Y. Lin, P. Zhao, X. Yu, S. Wang. H. Kang, and Y. Ding, 2013: The Beijing extreme rainfall of 21 July 2012: "Right results", but for wrong reasons. Geophys. Res. Lett., 40, 1426-1431, https://doi.org/10.1002/grl.50304.

- M. S. Jin, Y. Shou, and C. Dong, 2019: The influences of urban building complexes on the ambient flows over the Washington-Reston region. J. Appl. Meteor. Climatol., 58, 1325-1336, https://doi.org/10.1175/JAMC-D-19-0037.1.

Zhang, H., and Coauthors, 2019: Effect of urban expansion on summer rainfall in the Pearl River Delta, South China. J. Hydrol., 568, 747-757, https://doi.org/10.1016/j.jhydrol.2018.11.036.

Zhang, R., and Coauthors, 2011: South China Heavy Rainfall Experiments (SCHeREX). J. Meteor. Soc. Japan, 89A, 153-166, https://doi.org/10.2151/jmsj.2011-A10.

Zhong, L., R. Mu, D. Zhang, P. Zhao, Z. Zhang, and N. Wang, 2015: An observational analysis of warm-sector rainfall characteristics associated with the 21 July 2012 Beijing extreme rainfall event. J. Geophys. Res. Atmos., 120, 3274-3291, https:// doi.org/10.1002/2014JD022686.

Zhou, X., and Coauthors, 2003: Torrential Rainfall Experiment over Both Sides of the Taiwan Strait and Adjacent Area (HUAMEX) (in Chinese). Meteorology Press, 220 pp.

Zipser, E. J., 1977: Mesoscale and convective-scale downdrafts as distinct components of squall-line structure. Mon. Wea. Rev., 105, 1568-1589, https://doi.org/10.1175/1520-0493(1977) $105<1568$ :MACDAD $>2.0 . \mathrm{CO} ; 2$. 